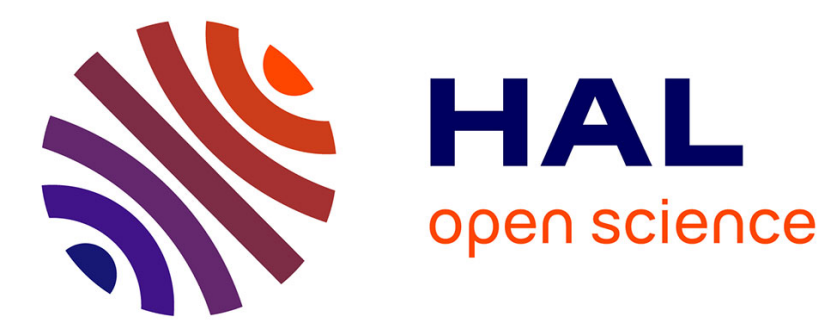

\title{
Oil Price Shocks, Real Economic Activity and Uncertainty
}

Amélie Charles, Chew Lian Chua, Olivier Darné, Sandy Suardi

\section{To cite this version:}

Amélie Charles, Chew Lian Chua, Olivier Darné, Sandy Suardi. Oil Price Shocks, Real Economic Activity and Uncertainty. Bulletin of Economic Research, 2021, 73 (3), pp.364-392. 10.1111/boer.12252 . hal-03284089

\section{HAL Id: hal-03284089 \\ https://hal-audencia.archives-ouvertes.fr/hal-03284089}

Submitted on 13 Jul 2021

HAL is a multi-disciplinary open access archive for the deposit and dissemination of scientific research documents, whether they are published or not. The documents may come from teaching and research institutions in France or abroad, or from public or private research centers.
L'archive ouverte pluridisciplinaire HAL, est destinée au dépôt et à la diffusion de documents scientifiques de niveau recherche, publiés ou non, émanant des établissements d'enseignement et de recherche français ou étrangers, des laboratoires publics ou privés. 


\title{
Oil Price Shocks, Real Economic Activity and Uncertainty
}

\author{
Amélie Charles \\ Audencia Business School \\ Chew Lian Chua \\ University of Nottingham, Ningbo \\ Olivier Darné \\ University of Nantes \\ Sandy Suardi \\ University of Wollongong
}

\begin{abstract}
This paper develops a structural factor vector autoregressive (SFVAR) model to study the effect of oil price shock on economic activity. The model allows both types of uncertainty (real economic activity and oil price) to directly affect oil prices and economic activity. More importantly, the factor variable, which is akin to the macroeconomic uncertainty measure of Henzel and Rengel (2017), captures the significant indirect spillover effects of both supplyrelated (oil prices) and demand-related (business cycle) shocks on oil prices and economic activity. By incorporating the indirect effect of this macroeconomic uncertainty, the response of economic activity to oil price shocks is amplified. In some countries the real effect is prolonged. Results for net oil exporting (importing) countries show that an oil price hike has an appreciably positive (negative) effect on economic activity. The factor dynamics of all countries, except for France, are highly correlated with each other, while they are all moderately correlated with some commonly used measures of macroeconomic uncertainty.
\end{abstract}

Keywords: Oil price uncertainty, Real Uncertainty, Impulse response, Outliers, Factor model. JEL: G10, C32, C38, E32. 


\section{Introduction}

The effect of uncertainty about the future course of the economy on economic activity has been a topic of significant interest amongst economists. A stream of research has identified uncertainty as a potential driving force of business cycle fluctuations (see Bloom, 2009; Grier and Perry, 2000; Bachmann, Elstner and Sims, 2013; Jones and Enders, 2016, amongst others). The literature has also identified that this uncertainty can originate from inflation uncertainty (Friedman, 1977; Ball, 1992), production uncertainty (Grier and Perry, 2000; Grier et al., 2004; Fountas et al., 2006), policy uncertainty (Baker, Bloom and Davis, 2013; Born and Pfeifer, 2014), and oil price uncertainty (Elder and Serlestis, 2009; Bredin et al., 2014; Charles et al., 2019). More recently, unprecedented oil price fluctuations coupled with rising macroeconomic uncertainty, partly engendered by crises, have generated interest on the response of output growth to oil price shock in the presence of macroeconomic uncertainty. ${ }^{1}$ In this stream of work, the deleterious effects of oil price shock and oil price uncertainty on economic activity have been examined without due consideration given to the effect of macroeconomic uncertainty on macroeconomic performance (Elder and Serletis, 2009; Bredin et al., 2011; Charles et al., 2019). This paper, therefore, proposes a novel method to study the dynamic linkages of economic activity and oil price shocks in the presence of macroeconomic uncertainty.

Why does economic uncertainty invariably affect the dynamics of oil prices? Firstly, there is an established literature that economic uncertainty can cause both the demand and supply of oil to be less responsive as a result of the option value to wait. Consequently, the elasticity of oil supply is lower since oil producers prefer to delay production until more information on demand shock is available (Litzenberger and Rabinowitz, 1995; Guiso and Parigi, 1999; Bloom et al.,

\footnotetext{
${ }^{1}$ The global financial crisis and the European debt crisis have had far-reaching effects on global economic growth and oil demand.
} 
2007; Bloom, 2009; Mohn and Misund, 2009; Kellogg, 2014). Secondly, uncertainty influences price setting in the oil spot and futures markets. Ellen and Zwinkels (2010) and Singleton (2013) argue that heterogeneous beliefs stemming from uncertainty in future economic activity will lead to oil price drifts and irrational volatility, even booms or busts. Thirdly, oil futures markets may respond quickly to economic uncertainty and transfer information to oil spot markets. Alquist and Kilian (2010) demonstrate that increased uncertainty about future oil supply shortfalls under plausible assumptions causes the spread to decline. Increased uncertainty also causes precautionary demand for oil to increase, resulting in an immediate increase in the real spot price. The authors also provide an empirical analysis of this indicator, providing evidence of how shifts in uncertainty about future oil supply shortfalls affect the real spot price of crude oil. Consistent with the view that hedging against oil price movements could weaken the responsiveness of oil demand and supply (Baumeister and Peersman, 2013), greater macroeconomic uncertainty would lead to an increased use of futures contracts, therefore decreasing the elasticity of oil demand and supply. While there is evidence to suggest that uncertainty affects oil price dynamics, to the authors' knowledge, only recently have researchers studied the dynamic linkages between uncertainty and oil returns (see Yin, 2016 and Aloui et al., 2016). We consider the direct and indirect effects of uncertainty on both oil price returns and real economic activity using a novel framework.

In this paper, we develop a novel empirical model to examine the effect of oil price shocks on output growth in the presence of uncertainty. Our proposed model brings together the literature on the effect of real (or output growth) uncertainty and oil price uncertainty when studying the effect of oil price shocks on economic activity. Our starting point is the structural vector autoregressive (SVAR) GARCH-in-Mean specification of Elder and Serletis (2009), 
which incorporates oil price uncertainty in the mean specification. We extend this model to incorporate the effect of real uncertainty on the dynamic of oil price and economic activity. Conventional practice is to model both types of uncertainty using the generalized autoregressive conditional heteroscedasticity (GARCH) (see Grier et al., 2004; Charles et al., 2019). Another important and distinct feature of our model is the inclusion of a factor variable, which captures the indirect transmission of oil price shocks and business cycle shocks on the macroeconomy through macroeconomic uncertainty. Our factor approach is motivated by Henzel and Rengel (2017), who identify two fundamental second-moment shocks in the U.S. macroeconomy based on a large dataset of individual uncertainty measures. The first fundamental shock triggers uncertainty associated with demand-related variables, for example the aggregate production and capacity utilization. For this reason it is termed "business cycle uncertainty". The second fundamental shock affects uncertainty associated with supply-related variables like oil and commodity prices and it is therefore interpreted as "oil price uncertainty". The factor captures the indirect uncertainty spillover effect on economic activity and oil prices. By incorporating the factor in the SVAR GARCH-in-Mean specification, the proposed model captures not only the direct effect of oil price uncertainty and real uncertainty on economic activity, it also permits indirect effect of macroeconomic uncertainty caused by the two fundamental shocks to impact on both oil price and economic activity. Figure 1 provides a flow chart diagram that embodies the notion of uncertainty arising from oil price and real economic activity, and the factor variable which represents the general notion of macroeconomic uncertainty influencing real economic activity. The Structural Factor Vector Auto-Regressive (SFVAR) GARCH-in-Mean specification model extends and nests the model developed by Elder (2003, 2004) and Elder and Serletis (2009).

-Figure 1 about here - 
Using the novel empirical model, we study the effect of oil price shocks on economic activity in the presence of direct and indirect shocks transmission in three oil net importing countries (the United States, France, and Japan) and three oil net exporting countries (Norway, Canada and the United Kingdom). Economic theory predicts that an increase in oil price may benefit an oil exporting country as opposed to an oil importing country given that oil exports would generate greater exports revenue. The transmission mechanisms through which oil prices impact on real economic activity can operate through both supply and demand channels. The supply side effects stem from crude oil as a basic input to production so that an increase in oil price leads to a rise in production costs, forcing firms to lower their output. Oil price changes also entail demand-side effects on consumption and investment. Consumption is affected indirectly through its positive relationship with disposable income. The magnitude of this effect is in turn stronger the more the shock is perceived to be long-lasting and the greater is the presence of macroeconomic uncertainty (Charles et al., 2019). Further, oil prices have an adverse impact on investment by increasing firms' costs. ${ }^{2}$ Following the existing literature that focuses on the study of the effects of macroeconomic uncertainty and oil price uncertainty on economic activity, our analysis follows a bivariate specification.

Blanchard and Gali (2000) and Charles et al. (2019) document the influence of extreme oil shocks and changing oil price uncertainty dynamics in the post-1985 period associated with economic and political events. Failure to properly account for the underlying dynamics of oil prices can give rise to an integrated and explosive volatility process which has ramifications for

\footnotetext{
${ }^{2}$ While oil price changes impact directly on supply and demand, they also influence foreign exchange markets and inflation, thus potentially giving rise to indirect effects on real activity. Although arguably a fully-fledged model controlling for other macroeconomic variables like inflation and exchange rates is worth exploring, it is computationally complex when incorporating these variables and estimating a four-variable multivariate SFVAR GARCH-in-Mean model.
} 
inference and the derivation of the impulse response function of real output to oil price shock obtained from an SVAR GARCH-in-Mean model. For this reason, our model is estimated on filtered series which account for possible outliers in the oil price dynamics over the period from 1985 to 2015 . Given that our model incorporates the indirect shocks transmission via a factor term in the mean specification, the impulse response function does not follow the standard VAR model or the SVAR GARCH-in-Mean model of Elder and Serletis (2009). Chua et al. (2012) derive the closed form analytical expression of the impulse response function for an SFVAR GARCH-in-Mean model, which we estimate. Comparison of the impulse response functions across models which incorporate direct and indirect volatility (or uncertainty) transmission highlights differences in the response of economic activity to oil price shocks. By and large, we find that the inclusion of indirect shocks transmission gives rise to an appreciably larger response in economic activity in the first couple of months following a positive oil price shock.

Our findings can be summarized as follows. There is evidence that in addition to the effects of oil price uncertainty and real uncertainty on economic activity and oil price dynamic, macroeconomic uncertainty also wields an indirect effect on these variables. We find that the indirect uncertainty transmission has an adverse effect on oil importing countries (the U.S.) but has positive effects on oil exporting ones (Canada and Norway). The Akaike information criterion chooses the SFVAR GARCH-in-Mean model in five of the six countries supporting the importance of the indirect transmission of shocks. ${ }^{3}$ The impulse response function generated by the model which incorporates indirect shocks transmission gives rise to a larger and, in some instances, a prolonged response in output growth to oil price shocks. An oil price hike is

\footnotetext{
${ }^{3}$ Using the Schwarz information criterion (SIC) chooses the SFVAR GARCH-in-Mean model in four of the six countries, which also supports the importance of the indirect transmission of shocks.
} 
associated with a contraction (expansion) in economic activity for oil importing (exporting) countries. When studying the factor dynamics of the sample of countries, we find that they are highly correlated with each other with the exception of France.

The rest of this paper is structured as follows. Section 2 introduces the SFVAR GARCHin-Mean model which is used to study the response of output growth to oil price shock in the presence of direct and indirect uncertainty transmission. Section 3 describes the data for a selected sample of oil importing and exporting countries. In this section, we also discuss the treatment of the data following identification of outliers in the data, which have ramifications for estimating the multivariate GARCH model. Section 4 presents the empirical results. Section 5 concludes the paper with a summary of the main themes explored here.

\section{The model}

The empirical model is a structural VAR with both factor and multivariate GARCH-inMean, which is a variant of Elder's (2003 and 2004) model. The SVAR model includes two variables: output growth and change in oil prices. The choice of the two variables is consistent with the recommendation of Elder and Serletis (2009) and Edelstein and Kilian (2007) who argue

that the bivariate VARs in output growth and the change in price of oil are adequate and appropriate for summarizing the relevant dynamics. The model is as follows:

$$
\begin{gathered}
A y_{t}=B f_{t}+\Gamma\left(L_{p}\right) y_{t-1}+\Lambda h_{t}+e_{t} \\
f_{t}=\rho f_{t-1}+G e_{t}
\end{gathered}
$$


where $e_{t} \mid \Omega_{t-1} \sim N\left(0, H_{t}\right) . \Gamma\left(L_{p}\right)$ is a 2-dimensional conformable lag polynomial matrix of finite order. $\Lambda$ is an $2 \times 2$ coefficient matrix which captures the effects of oil price uncertainty and real uncertainty on economic activity and changes in oil price. ${ }^{4}$ Uncertainty attributed to economic activity and changes in oil price are captured in the column vector, $h_{t}=\left[\begin{array}{ll}h_{I P I, t} & h_{O i l, t}\end{array}\right]^{\prime} . A$ is $2 \times 2$ coefficient matrix. Specifically, $A$ is an upper triangular matrix such that $A=\left[\begin{array}{cc}1 & 0 \\ a_{21} & 1\end{array}\right] . B$ is a $2 \times 1$ vector whereby $B=\left[\begin{array}{l}1 \\ b\end{array}\right]$. Elements in this loading vector indicate the relative contributions of $f_{t}$ to output growth and the change in oil price equations. Because $f_{t}$ is latent and the loading vector is unknown, to ensure these are estimable we restrict the first element of the loading vector to 1 (see Bai and Wang, 2015 for a discussion on identification in dynamic factor models). Here, $y_{t}=\left[\begin{array}{ll}\Delta I P I_{t} & \Delta O i l_{t}\end{array}\right]^{\prime}$ and $e_{t}=\left[\begin{array}{ll}e_{I P I, t} & e_{O i l, t}\end{array}\right]^{\prime}$. We further assume that $\operatorname{Cov}\left(e_{I P I . t} e_{O i l, t}\right)=0$. Note also that the specification in equation (1) orthogonalizes the reduced form errors by allowing $\Delta O i l_{t}$ to depend on contemporaneous $\Delta I P I_{t}$ through the coefficient $a_{21}$ while restricting $\Delta O i l_{t}$ from influencing $\Delta I P I_{t}$ contemporaneously. This restriction implies that $\Delta O i l_{t}$ responds quickly to innovations in $\Delta I P I_{t}$ while $\Delta I P I_{t}$ responds to $\Delta O i l_{t}$ innovations with a one-month lag. This restriction is deemed appropriate given that oil is traded as a commodity and its price adjusts rapidly to new information. By orthogonalizing the reduced form errors with this restriction, we are able to identify the structural coefficients. The assumption that $\Delta O i l_{t}$ responds contemporaneously to $\Delta I P I_{t}$ can be tested via the significance of the $a_{21}$ coefficient estimate based on the data.

Equation (2) shows that the factor is governed by two fundamental second-moment shocks in the macroeconomy, namely the oil price shock and output shock. The shock loading is

\footnotetext{
${ }^{4}$ Elder (2004) estimates a four-variable SVAR model with multivariate GARCH-in-Mean. However, he restricts some coefficients of $\Lambda$ to zero. In our model, we do not impose zero restriction on the coefficients of $\Lambda$.
} 
determined by the elements in $G$, which is a $1 \times 2$ vector. The factor evolves as an autoregressive process with lag order 1 and the loading coefficient of the lagged dependent variable is given by $\rho$. The two fundamental second-moment shocks in the macroeconomy, which have been identified by Henzel and Rengel (2017) as the important dimensions of macroeconomic uncertainty, characterize the factor dynamics. The factor is in turn incorporated in the mean specification (1) together with oil price uncertainty and real uncertainty. The importance of this factor in determining oil prices and economic activity is captured by the loading vector $B$.

In equation (1), the $2 \times 1$ vector of observable variables, $y_{t}$ follows a vector autoregressive process whose lag order is determined by the Schwarz Criterion (SC), and its dynamic is determined by a multivariate GARCH-in-Mean process, which captures the possible effect of changes in oil price uncertainty and real uncertainty on both oil price changes and output growth. Given $\Omega_{t-1}$ is the information set at time $t-1, e_{t} \mid \Omega_{t-1} \sim N\left(0, H_{t}\right)$ such that $H_{t}$ follows a diag form multivariate GARCH process. Note that we do not model the conditional covariance of changes in oil price and output growth so we set this term to zero. The diag model is a direct generalization of the univariate GARCH and assumes that $H_{t}$ is determined by reference to past errors and historical volatility:

$$
\begin{gathered}
h_{t}=\operatorname{diag}\left(H_{t}\right)=A_{1}+A_{2} \operatorname{diag}\left(e_{t-1} e^{\prime}{ }_{t-1}\right)+A_{3} h_{t-1} \\
e_{t}=H_{t}^{0.5} z_{t} \text { and } z_{t} \sim \text { i.i.d } d(0, I)
\end{gathered}
$$

where $A_{1}$ is a $2 \times 1$ vector, $A_{2}$ and $A_{3}$ are $2 \times 2$ matrices, and $A_{1}, A_{2}$ and $A_{3}$ are appropriately restricted to ensure that $H_{t}$ is a symmetric positive definite matrix (see Bollerslev et al., 1988). Since the conditional covariance of changes in oil price and output growth is assumed to be zero, 
the off-diagonal elements of $A_{1}, A_{2}$ and $A_{3}$ are set to zero. Our measure of oil price uncertainty is $h_{O i l, t}$ the conditional variance of oil, which represents the one-month ahead forecast for oil price change and the dispersion of the forecast error. ${ }^{5}$ The greater is $h_{O i l, t}$ the more uncertain is the impending realization of oil prices. The output growth uncertainty is $h_{I P I, t}$ the conditional variance of changes in the IPI, which represents the one-month ahead forecast of changes in IPI and the dispersion of the forecast error. The greater is $h_{I P I, t}$ the greater is real uncertainty. The effect of real uncertainty and oil price uncertainty on output growth is captured by the parameter $\lambda_{11}$ and $\lambda_{12}$, respectively, in the $\Lambda$ matrix in equation (1). If the real effect of oil price uncertainty tended to retard output growth, then the $\lambda_{12}$ estimate should be negative and significant. Similarly, if the real effect of output growth uncertainty tended to decrease output growth, then the $\lambda_{11}$ estimate should also be negative and significant. We also permit both real uncertainty and oil price uncertainty to influence changes in oil prices; the effects are captured by the parameters $\lambda_{21}$ and $\lambda_{22}$, respectively. The parameters in equations (1) to (4) are estimated using the method of maximum likelihood. Note that given equation (2) and the initial state $f_{0}$, the model's $\log$ likelihood function is

$$
\log L\left(A, B, \Gamma, \Lambda, G, \rho, f_{0}, A_{1}, A_{2}, A_{3} ; y_{t}\right)=-\frac{1}{2} \sum_{t=1}^{T} \log \left|H_{t}\right|+\log \left(\hat{e}_{t}^{\prime} H_{t}^{-1} \hat{e}_{t}\right)
$$

where $\hat{e}_{t}=y_{t}-\hat{y}_{t}$. Estimates of the parameters may be obtained by maximizing (5) with respect to the parameter set. The maximum likelihood estimation of models encompassing a single source of error is discussed in Ord et al. (1997). Snyder (1985) also shows that any model of the form described in this section has a heteroskedastic ARIMA representation. Tsiaplias and Chua

\footnotetext{
${ }^{5}$ Elder and Serletis (2009) and Charles et al. (2019) use the conditional standard deviation of oil price changes as a proxy for oil price uncertainty in the mean specification. We do not use this proxy because the impulse response function requires linearization of the square root function in the case that the conditional standard deviation is employed. Chua et al. (2012) and Elder (2003) use the conditional variance in the derivation of the SVAR GARCHin-Mean impulse response function. Our empirical point estimate for the coefficient associated with $h_{\text {Oil },}$ is very small so it is possible that the use of conditional standard deviation may lead to an improvement in the fit. However, this is at the expense of not being able to obtain an exact analytical expression for the impulse response function.

${ }^{6} \mathrm{We}$ set the initial state by taking the average of the first ten observations of $\mathrm{y}_{\mathrm{t}}$.
} 
(2013) show in a Monte Carlo experiment that the maximum likelihood estimator for a model specification similar to ours but with Student's t innovation has little bias and that the variance of the parameters is close to the mean square error. Our model is coded and estimated in a MATLAB environment. ${ }^{7}$

An important difference between our model and the Elder and Serletis model (2009) is that we consider: (1) the possibility of real uncertainty influencing both oil price and economic activity; (2) the possibility for oil price uncertainty affecting not only real economic activity but also oil price dynamics - a relationship which is found to be pertinent as evidenced by Yin (2016) and Aloui et al. (2016); and (3) the inclusion of a factor which is governed by the two fundamental second-moment shocks in the macroeconomy impacting on both oil price and economic activity - this is also the notion of indirect shocks transmission through macroeconomic uncertainty. Setting the vector B to zero and restricting the $\Lambda$ coefficient matrix to take into account only the effect of oil price uncertainty on real economic activity (i.e. $\lambda_{12}=\lambda_{21}=\lambda_{22}=0$ ) reduces the mean specification in equation (1) to the model of Elder and Serletis (2009). The inclusion of the factor model, which captures the indirect transmission of shocks, changes the impulse response function for a model that features a GARCH-in-Mean term (Elder 2003). Chua et al. (2012) derive the closed form expression of the impulse response function for a SFVAR GARCH-in-Mean model. We estimate three models, namely the SVAR GARCH-in-Mean model of Elder and Serletis (2009), the SFVAR GARCH-in-Mean model incorporating only the effect of oil price uncertainty, and the SFVAR GARCH-in-Mean model which incorporates both oil price uncertainty and real uncertainty. The impulse response functions derived from these three models are subsequently compared.

\footnotetext{
${ }^{7}$ The MATLAB program for estimating the model is available from the authors upon request.
} 


\section{Data and outliers}

\subsection{Data source and summary statistics}

Our data for output growth, which is proxied by the industrial production index (IPI), are obtained from St. Louis FRED database and span the period from November 1973 to December $2015 .^{8}$ Industrial production (IP) has been widely used as a measure of real economic activity at country level (see Grilli and Roubini, 1996; Bernanke et al., 1997; Kim and Roubini, 2001). This stems from the historical observation that the value added by IP represented a substantial share of GDP. It is no surprise that the IP continues to be widely used as a monthly indicator for assessing both the current state and short-term outlook for GDP (see among others NBER's Business Cycle Dating Committee, Mitchell et al., 2005; Golinelli and Parigi, 2007; Angelini et al., 2011; Brunhes-Lesage and Darné, 2012). In addition, IPI data measure output production in industries that are both energy intensive and extensive with such industries including mining, manufacturing and utilities. ${ }^{9}$ Mining industries engage in direct exploration of oil and gas and other energy intensive mining operations. Manufacturing and utilities industries are equally energy intensive. The output data are seasonally adjusted at 2012 constant prices. Bredin et al. (2011) point out a potential problem with the inclusion of IPI data in 2008 when the global financial crisis had an adverse impact on output growth in the U.S. and Canadian economies, to the extent that measuring the impact of oil price uncertainty on output growth may be biased by the adverse effect of the crisis. This issue, however, does not present a problem for our analysis because the outlier detection in the mean of output growth identifies the adverse effect of the financial crisis on output growth and the output growth series can be adjusted for this effect.

\footnotetext{
${ }^{8}$ The data are obtained from the following URL: https://fred.stlouisfed.org/

${ }^{9}$ While aggregate investment data may be deemed more appropriate, the downside of using such data is that many of the industries, for example, software industries, included in aggregate investment are not energy intensive. Data for aggregate investment exist at a lower frequency, usually quarterly. Lastly, aggregate investment data do not include production decisions and hence the real options component which is sensitive to oil or energy prices may not be adequately reflected in the data (Bredin et al., 2011).
} 
For oil prices they are measured in nominal local currency. Like Blachard and Gali (2007), Bredin et al. (2011), and Charles et al. (2019) nominal oil prices are preferred to real oil prices for the reason that the former allows the isolation of uncertainty associated with oil prices from uncertainty associated with the aggregate price level. The U.S. oil price is the cost of imported crude oil free on board, which is approximately the average of OPEC and non-OPEC free on board crude oil prices since the U.S. imports oil largely from Canada and other OPEC countries. For the other countries, we use the U.S. FOB costs of non-OPEC countries' crude oil prices (measured in dollars per barrel). The oil price is then converted to local currency using nominal exchange rates obtained from the St. Louis FRED database. The oil price series are obtained from the U.S. Department of Energy. ${ }^{10}$

It has been previously documented in the literature that the oil price dynamic appears to have undergone regime changes after mid-1985 (Charles et al., 2019; Baumeister and Peersman, 2011; Blanchard and Gali, 2000). Charles et al. (2019) document the systematic increase in the volatility of crude oil prices since July 1985 by dating the structural break in oil price return volatility. This break date coincides with the finding of Baumeister and Peersman (2010), who argue that the rise in oil price volatility since 1986 is attributed to decreasing short-run price elasticities of oil supply and oil demand. The lack of spare oil production capacity and limited investment in oil industry following the mid-1980s further led to an increase in oil price volatility. At the same time, this increased uncertainty has deepened oil futures markets leading to further reduction in the sensitivity of oil supply and demand to changes in crude oil prices. Blanchard and Gali (2000) document that the real effects of oil price shocks have changed

\footnotetext{
${ }^{10}$ The data for oil prices are obtained from the URL $\underline{\text { www.eia.gov }}$
} 
substantially over time with much larger effects of oil price shocks on inflation and activity found in the 1970s compared to the post-1984 period. They attribute this change to the more flexible labor markets arising from more flexible wages, which bring about the smaller impact of the more recent oil shocks, changes in the way monetary policy is conducted by way of explicit inflation-targeting strategies, and a significant decline in the share of oil in the economy. On the basis of the established regime change in the impact of oil price shocks on real economic activity, we perform our analysis for the period July 1985 to December 2015.

-Table 1 and Figure 2 about here -

Table 1 presents summary statistics of the data. Output and oil prices are also expressed in annualized growth rate, each is denoted by the log first difference of the series multiplied by 1200 , so that $\Delta I P I_{t}=1200 \times \ln \left(\frac{I P I_{t}}{I P I_{t-1}}\right)$ and $\Delta O i l_{t}=1200 \times \ln \left(\frac{O i l_{t}}{O i l_{t-1}}\right)$, respectively. All series show deviation of skewness and kurtosis from zero except for the $\Delta I P I_{t}$ of France and Canada. The Jarque-Bera test of normality strongly rejects the null of normality for all series. The ARCH test also indicates significant evidence of conditional heteroskedasticity in the data, at least up to lag order 6. The Augmented Dickey-Fuller (ADF) test rejects the null of a unit root in all series, thus suggesting all series are stationary. However, a cursory look at the plots of the series (see Figure 2) suggests there are some outliers in both $\Delta O i l_{t}$ and $\Delta I P I_{t}$ series. Looking at Panel 2 of Figure 2, some of the spikes and plunges in oil price changes reflect the following events: the Iran-Iraq War initiated in 1980, the first Persian Gulf War in 1990-91, the oil price spike of 20072008, and the oil price plunge of 2015. For output growth (Panel 1), there are apparent dips in the U.S. arising from the 2008-2009 global financial crisis, and in Japan in 2009 from the global 
financial crisis and in 2011 from the Fukushima power plant disaster caused by the earthquake and tsunami.

\subsection{Additive outliers in oil price and IPI}

Prior to estimating the model, we take issue with possible outliers in the data, which Charles and Darné (2014) and Charles et al. (2019) show could distort the volatility persistence and the impulse response functions, respectively. We use the Laurent et al. (2016) test based on the GARCH model on the first differenced data to identify possible data outliers. The reader is referred to Charles et al. (2019) for a discussion on the implementation of this test. The results are summarized in Table 2. Outliers are identified in both $\Delta I P I_{t}$ and $\Delta O i l_{t}$ for the six countries, except for $\Delta I P I_{t}$ in Canada and France. The dates for outliers in $\Delta O i l_{t}$ are in: 1986:2, which is associated with the oil price collapse in the first half of 1986 when oil prices fell to the 1974 price level. This was caused by excess oil supply from Saudi Arabia and some of its neighbors increasing their share of the oil market; 1990:8, which is associated with the first Gulf War and it is considered as both a supply shock and precautionary demand shock; 2008:10, which is due to the global financial crisis and is considered as a demand shock; and finally, 2014:12, which is driven by excess capacity of oil arising from the strong supply and stagnant demand. For the $\Delta I P I_{t}$ series, outliers are identified in 2008 for the U.S. due to the global financial crisis. In Japan, the outliers of 2008, 2009 and 2011 are associated with the deep recession like in the rest of the world due to the global financial crisis, and the recovery was set back by the March 2011 earthquake and tsunami. In Norway, the 1986 outliers are associated with the financial deregulation and boom that occurred in the period 1984-1987, which led to a boom in real estate and private consumption growth, while the 2002 outliers in the U.K. are associated with a steep decline in output growth rate relative to past years, which is in part driven by the stock market 
crash of September 11, 2002. These outliers are removed from the underlying series and the filtered series are employed when estimating the models.

- Table 2 about here -

\section{Empirical Results}

\subsection{Model estimates}

Table 3 shows the estimation results for the three models. Panel A reports the SFVAR GARCH-in-Mean model and Panel B reports the SVAR GARCH-in-Mean model without the factor (or indirect uncertainty transmission). Both models in Panels A and B only incorporate oil price uncertainty. Panel C is the SFVAR GARCH-in-Mean model which includes both oil price uncertainty and real uncertainty. The coefficient estimates of the lagged endogenous variables in the SFVAR and SVAR specifications are not reported for brevity. Only the parameters of interest are reported. For each model, the optimal lag order is determined using the Akaike information criterion (AIC). The lag order together with the log-likelihood values are reported in the first two rows of Table 3.

- $\quad$ Table 3 about here -

With regard to the restriction which presupposes that $\Delta O i l_{t}$ responds quickly to innovations in $\Delta I P I_{t}$ while $\Delta I P I_{t}$ responds to $\Delta O i l_{t}$ innovations with a one-month lag, we do not find any evidence that this is supported by the data for the SFVAR model with oil price uncertainty, except for the case of France (see Table 3 Panel A). For the SVAR GARCH-in-Mean model in Panel B, none of the results show that this assumption is supported by the data. On the other hand, for the SFVAR model with oil price uncertainty and real uncertainty in Panel C, only 
the U.S. and Canada demonstrate that oil price change responds quickly to innovations in output growth while the latter responds to oil price shocks with a one-month lag.

Referring to the factor specification, in Panel A only the coefficient of IPI shock (i. e. $g_{1}$ ) is statistically significant for France, while that of oil price shock (i.e. $g_{2}$ ) is statistically significant for the United States, Canada and Norway at the 5\% significance level. In Panel C, the coefficients of the IPI shock and oil price shock are statistically significant for both the U.S. and Canada at the 5\% significance level. Turning to the indirect shocks transmission via the factor term for the SFVAR model with oil price uncertainty, the factor term is shown to exert a statistically significant negative (positive) influence on the mean changes in the oil price for France (United Kingdom). With regard to the SFVAR model with oil price and real uncertainty, the factor exerts a statistically significant and negative influence on the mean changes in oil price in the U.S. However, it wields a positive influence for Canada and Norway. These results are intuitively interesting and suggest that the indirect volatility transmission arising from macroeconomic uncertainty has a negative (positive) impact on oil price in net oil importing (exporting) countries. One possible explanation is that the movement in oil price reflects either a demand shock or a supply shock. In the case of net oil importing countries, an increase in uncertainty has a negative effect on the economy, which in turn decreases demand for oil and its price. On the other hand, for net oil exporting countries, an increase in uncertainty causes oil suppliers to stock-up due to precautionary motive, which leads to an increased oil price. While the two effects could be at work at the same time, the net effect would give rise to the overall effect of macroeconomic uncertainty on oil price returns. 
The coefficient estimates for the multivariate GARCH model are by and large statistically significant at the $5 \%$ significance level. The coefficient of the lagged conditional variance for changes in oil price is noticeably larger than that of output growth, which is consistent with the empirical feature that changes in oil price volatility are more persistent than that of output growth. In Panel A, we find the deleterious effect of oil price uncertainty on output growth which has been previously documented in the literature. This is consistent with the theory of investment under uncertainty (Dixit and Pindyck, 1994) in which this literature identifies real-options effect as an important transmission channel of uncertainty on the real economy. The real-options effect is associated with irreversibility in investment, implying that heightened uncertainty makes firms more cautious about hiring and investing, and consumers more cautious about buying durables. While the coefficient estimate appears small in magnitude, this is not to be misconstrued that the effect is not economically significant. Our model specifies oil price uncertainty as the conditional variance of oil price residuals. This proxy is different from the conditional standard deviation used by Bredin et al. (2011) and Charles et al. (2019), inter alia. By reference to the coefficient estimate of $\lambda_{12}$ for the U.S., it can be seen that for a comparable proxy of $\sqrt{h_{I P I, t}}$, the estimate is about $0.02(=\sqrt{0.004})$ in absolute term, which is of a similar order of magnitude as the one reported by Bredin et al. (2011) and Charles et al. (2019). For the SFVAR model, oil price uncertainty continues to have a pernicious effect on economic activity in net oil importing countries like the U.S. and France, and the net oil exporting country, Canada. Similar evidence is found in the SVAR model of Panel B, at the 5\% level of significance. As for the SFVAR model incorporating both oil price uncertainty and real uncertainty, similar evidence is further found for the U.S. and Canada - the evidence of the growth reducing effect of oil price uncertainty is robust to the model specification considered. The U.K. also displays the pernicious effect of oil price uncertainty on output growth. 
Finally, real uncertainty is found to increase output growth and oil price changes in the U.S. as seen by the statistically significant coefficients $\lambda_{11}$ and $\lambda_{21}$. The positive effect of output growth volatility on the mean output growth is consistent with the view put forward by Black (1987) that investments in riskier technologies will be pursued only if the expected return on these investments (average rate of output growth) is large enough to compensate for the extra risk. Similarly, Blackburn (1999), in a study based on endogenous growth caused by learning-bydoing, shows that business cycle volatility raises the long-run growth of the economy. The significance in the $\lambda_{21}$ estimate which captures the effect of real uncertainty on the mean oil price changes is consistent with the findings of Ellen and Zwinkels (2010) and Singleton (2013), who show that heterogeneous beliefs by traders stemming from uncertainty in future economic activity would lead to oil price drifts. Oil price uncertainty, on the other hand, is found to have a negative effect on the mean oil price change in the U.S., the U.K. and Canada. The presence of heightened oil price uncertainty, which impedes investment, is likely to result in a fall in oil demand thus reducing oil prices.

- Table 4 about here -

To determine which of the three model specifications is best for characterizing the data we turn to the AIC for the model selection criterion. Given that a different order of lag length is chosen for each model and for each country, it is not possible to perform model selection test within the nested models using the likelihood ratio test. Table 4 shows that for oil importing countries, like Japan and France, the SFVAR GARCH-in-Mean model which incorporates both oil price uncertainty and real uncertainty is the preferred model specification. For the U.S. the SFVAR GARCH-in-Mean model which incorporates only oil price uncertainty is regarded as a 
better fit. For the oil exporting countries, both Canada and the U.K. are in favor of the SFVAR GARCH-in-Mean model with oil price uncertainty. Norway is the only country that is in favor of the SVAR GARCH-in-Mean model. Taken together, our results generally do support a model that incorporates the indirect transmission of shocks via the factor specification. When a stricter $^{11}$ information criterion is employed (i.e. the Schwarz information criterion) as is employed by Elder and Serletis $(2009,2010)$, the results continue to be in favor of the SFVAR GARCH-in-Mean model, with the exception of France.

\subsection{Impulse response functions}

Figure 3 shows the impulse response functions generated by the three models for the sample of six countries. For ease of visual comparison across the impulse response functions produced by the different models, we do not plot the confidence interval for the impulse response functions. ${ }^{12}$ For the U.S., we find that an oil price hike has the effect of reducing output growth in the months that follow - a finding commonly shared by all three impulse responses. The impulse response based on the SFVAR model which incorporates the indirect transmission of oil price and output shocks tends to observe an increase in output growth in the first quarter followed by a contraction in subsequent quarters. The overall effect is a prolonged response of real economic activity to the oil price shock. Based on the SFVAR model, we find that the initial increase in output growth by $1 \%$ in the U.S. economy is followed by rapid contractions in the following months. The same pattern of response can be observed for Japan, although the effect of oil price shock on output growth dissipates rapidly. The positive growth effect of an oil price hike in Japan in the first few months after the shock as indicated by the SFVAR and SVAR impulse

\footnotetext{
${ }^{11}$ The Schwarz criterion includes a substantive penalty for the additional parameters required to estimate GARCH models to the extent that any improvement in this criterion would provide strong evidence in favor of the allencompassing (i.e. both GARCH and the factor) model specification.

${ }^{12}$ The confidence intervals for each impulse response function are available from the authors upon request.
} 
response functions is consistent with the finding of Blanchard and Gali (2000). France's output growth decreases by about $0.5 \%$ in the first two months before the full effect of the shock dissipates after two quarters. It is important to highlight that the response of output growth to oil price shock shows stark contrast between the SVAR model which does not take into account the indirect transmission of shocks in the economy and the SFVAR models. The SVAR model impulse response shows a negligible reduction in output relative to the contraction observed in the impulse responses of the two SFVAR models.

- Figure 3 about here -

For oil exporting countries, we generally observe that an oil price hike results in economic expansion. For Canada, the optimal SFVAR model incorporating oil price uncertainty yields the blue impulse response function which signifies an increase in output growth by less than $0.5 \%$ in the first quarter before the effect of the oil price shock fully dissipates in the second quarter. For Norway, based on the impulse response function of the SVAR model, an oil price hike gives rise to an economic expansion by no more than $0.2 \%$ in the first quarter before the effect dissipates in the tenth month. In the U.K., an oil price hike brings about an economic expansion by about $0.5 \%$ before the effect subsides and is muted at the end of the first quarter (see the blue impulse response function). Again, we find that there is a distinction in the impulse response of the SVAR model and SFVAR models. The former reveals a contraction in output following an oil price hike which fails to accord with intuition. Overall, we do find that there are differences in the impulse response functions generated by SVAR and SFVAR models, signifying the importance of incorporating the indirect transmission of shocks which operate through uncertainty. 
For brevity, we do not report the impulse responses of economic growth in the presence of a negative oil price shock. We find that the response to economic activity is symmetric but in the reverse direction when compared to the effects of oil price hikes. These results are available from the authors upon request. While our approach to determining the symmetric nature of the responses of economic activity to oil price shocks is model dependent, we undertake a robustness test using the symmetry test method of Kilian and Vigfusson (2011). Their approach which uses an impulse-response-based test, however, does not take into consideration the direct and indirect impact of uncertainty on oil prices and economic activity.

\subsection{Symmetry test on the response of real economic activity to oil price increases and}

\section{decreases}

Kilian and Vigfusson (2011) demonstrate that in ensuring the consistency in the model estimates, the model specification needs to account for both energy price increases and decreases. ${ }^{13}$ Further when testing the symmetric responses of the economy to energy price increases and decreases, they propose a method of computing impulse responses that capture the time-dependent nature of these price shocks which differ from the traditional impulse responses that tend to overestimate the effect of a positive oil price shock. We estimate the general model that links oil price changes to the economy as follow:

$$
\begin{aligned}
& x_{t}=b_{10}+\sum_{i=1}^{p} b_{11, i} x_{t-i}+\sum_{i=1}^{p} b_{12, i} z_{t-i}+\varepsilon_{1, t} \\
& z_{t}=b_{20}+\sum_{i=0}^{p} b_{21, i} x_{t-i}+\sum_{i=1}^{p} b_{22, i} z_{t-i}+\sum_{i=0}^{p} g_{21, i} x_{t-i}^{+}+\varepsilon_{2, t}
\end{aligned}
$$

\footnotetext{
${ }^{13}$ Herrera et al. (2015) employed the symmetry test of Kilian and Vigfusson (2011) to evaluate the presence of asymmetries in the response of economic activity in a set of OECD countries to oil price increases and decreases. On the other hand, Kyritsis and Serletis (2019) employed the same test to determine the presence of asymmetric responses of stock returns to oil price increases and decreases.
} 
where $x_{t}=\Delta O i l_{t} \quad, z_{t}=\Delta I P I_{t}$ and $x_{t-i}^{+}=\max \left[0, x_{t}-\max \left\{x_{t-1}, x_{t-2, \ldots,} x_{t-12}\right\}\right]$ which is consistent with the definition in Hamilton (2013), that is net oil price increase over the past twelve months. Having estimated model (6), we follow the method of Killian and Vigfusson (2011) and simulate 10,000 impulse responses before calculating the average difference in the time path of $z_{t+h}$ for $h=0, \ldots, 12$ based on 100 histories of both $x_{t}$ and $z_{t}$. For detailed discussion of the simulation method the reader can refer to Kilian and Vigfusson (2011). The test statistic under the null hypothesis of symmetric impulse responses of $z_{t}$ to oil price increases and decreases of size $\delta$ is given by

$H_{0}: I_{z}(h, \delta)+I_{z}(h,-\delta)=0$ for $h=0,1, \ldots, 12$.

The test statistic which depends on the size of oil price shock $\delta$ follows a $\chi_{H+1}^{2}$ distribution where $H=12$. We report the results in terms of $p$-value for the symmetry test of impulse responses to small (one-standard-deviation) and big (two-standard-deviation) oil price shocks in Table 5.

- Table 5 about here -

Referring to column (1), the asymmetric response of real economic activity to a standard deviation of oil price shock varies with time. By and large, over the short-run forecast horizon of $h=1,2$, and 3 , the test rejects null hypothesis of symmetry at 5\% level implying that the U.S. economy responds asymmetrically to oil price increases and decreases. However, for the longer forecast horizons (i.e. $h=4, \ldots, 12$ ), the test fails to reject the null hypothesis of symmetry. This pattern of results is commonly found in the other five countries with the response of real GDP growth to positive and negative oil price shocks failing to display asymmetry from forecast periods 6 to 12 months. For big shocks (see column (2)), the test rejects the null hypothesis of symmetry over all forecast periods other than $h=0$ for all countries in our sample. While we find mixed findings of symmetric responses of the economy to oil price increases and decreases over the different forecast horizons, and these results differ from our findings based on impulse 
responses generated by our model with direct and indirect volatility spillover effects, we attribute these differences to (1) that the models used to generate these impulse responses are different, and (2) the impulse responses are also computed differently for these two models. On the bases of our findings, the literature concludes that the asymmetry typically found in the oilmacroeconomic relationship tends to be exaggerated due to the flawed method used for assessing this relationship. When we employ the method of Kilian and Vigfusson (2011) which circumvents the problem of inefficient and inconsistent estimates, we find that the asymmetric response of real GDP growth to oil price increases and decreases occur only in the short-run while the response of real GDP growth can be viewed as symmetric in the long-run for a standard deviation positive and negative oil price shock.

\subsection{Synchronization of the factors and correlations with uncertainty measures}

To better understand the similarities or differences of the estimated factors of the six countries, we report in Table 6 the correlation matrix for the six countries' estimated factors. It can be seen that by and large the factors for the U.S., Japan, Canada, Norway and the U.K. are highly correlated. ${ }^{14}$ This is not surprising as these factors - which are driven by business cycle shocks and oil price shocks - are expected to be alike particularly with increased global economic integration. Nonetheless, we do not find that the factor dynamic for France is highly correlated with those of the other five countries. Figure 4 shows the smoothed factor series plot of the six countries. The smoothed factors are obtained by using the Hodrick-Prescott band-pass filter. ${ }^{15}$ It is evident that unlike France the smoothed factors of the other five countries resemble each other. Be that as it may, there are two common characteristics in all countries smoothed factor series.

\footnotetext{
${ }^{14}$ There is, by and large, a marginal improvement in the correlation of smoothed factors relative to the "noisier" estimated factors series.

${ }^{15}$ As low-pass filter, we use the Hodrick-Prescott filter with the appropriate tuning parameter $(\lambda=13.9)$ to eliminate fluctuations with a frequency higher than one year.
} 
The 1986 oil price shock due to the Iran-Iraq war and the effect of the 2008/2009 global financial recession are evident in the two significant drops of the factor estimates.

- $\quad$ Table 6 and Figure 4 about here -

Given that these macroeconomic uncertainty factors are to some degree driven by country-specific business cycle shocks and the more universal oil price shocks, we detect classical cycle turning points to understand the extent by which these countries' macroeconomic uncertainties are synchronized. To this end, we apply the widely used business cycle dating algorithm on the monthly estimated factor series following the non-parametric automated procedure introduced by Bry and Boschan (1971). This specific algorithm basically replicates the expert system for detecting turning points developed at the NBER and codifies the procedures applied by Burns and Mitchell (1947). While the factor is not entirely driven by country-specific business cycle shocks and also contains worldwide oil price shocks, we are able to assess the extent of cyclical fluctuations in the factor series by locating the exact switch points from an expansion to a contraction and vice versa. This is achieved through the procedure of identification of local minima and maxima in the path of the underlying factor series, using a general rule, so that a peak and a trough, respectively, are given if $\left\{y_{t}>y_{t-k}, y_{t}>y_{t+k}, k=\right.$ $1, \ldots, M\}$ and $\left\{y_{t}<y_{t-k}, y_{t}<y_{t+k}, k=1, \ldots, M\right\}$. Following Burns and Mitchell's (1947) dating procedure, we set $\mathrm{M}=5$ for monthly data and apply specific censoring rules. ${ }^{16} \mathrm{We}$ use the

\footnotetext{
${ }^{16}$ As indicated by Harding (2003, pp. 3-4), the most important reason for censoring turning points is to enhance the effect of nonlinearities. In the case, specifically, of nonlinearities large changes are expected to differ significantly from small changes and nonlinearity is expected to show up in the path taken between successive turning points. In that sense, censoring is implemented in order to ensure that phases are sufficiently long so as to make any nonlinearity evident.
} 
program implementation of the BB business cycle dating algorithm provided by Watson (1994). ${ }^{17}$ The appendix provides an overview of the $\mathrm{BB}$ formulation which involves a preliminary determination of cycles and a gradual narrowing down of neighborhoods within which turning points are selected.

- Table 7 about here -

It can be seen in Table 7 that the average duration of contractions for all five countries but one is in the range of 4 and 5 months. France's average duration of contraction is the highest at about 8 months. Similarly, France has an equally longer average duration of expansions of about 8.4 months. On the other hand, the other five countries have an average duration expansion of about 5 to 6 months, which is longer than the average duration of contractions. It is possible that given the longer duration of expansions and contractions for France we find the factor for France is less synchronous and less correlated with those factors of the other countries. This can be explained by the fact for France nuclear energy and gas have taken a large part in industrial production and substituted for oil since the 80's.

- $\quad$ Table 8 about here -

Finally, we compare our factor estimates with three measures of economic uncertainty, namely Kilian's real index, economic policy uncertainty proposed by Baker et al. (2016), and the macroeconomic uncertainty measure developed by Jurado et al. (2015). Kilian's real index is a proxy for global economic activity related to commodities computed from cargo ship freight rates

\footnotetext{
${ }^{17}$ The basic GAUSS code for the implementation of the BB business cycle dating algorithm is taken from www.princeton.edu/\%7Emwatson/publi.html.
} 
(Kilian, 2009). ${ }^{18}$ Global real activity is used as a proxy of demand for all commodities including crude oil. Fluctuations in demand can bring about fluctuations in oil price. Table 8 shows the correlation estimates for the respective country smoothed factor series with the different uncertainty measures. The correlation with Kilian's real index over the 0.30 to 0.35 range, suggests that the factor series which is partly made up of oil price shocks shows some degree of comovements with fluctuations in oil demand as proxied by Kilian's real index. To quantify economic policy uncertainty, Baker, Bloom, and Davis (2016) propose a measure calculated from the frequency that policy uncertainty is mentioned in media, the number of taxation policy changes, and the heterogeneity in professional forecasts of inflation and government spending. The correlation between each country's estimated factor series and the respective country's economic policy uncertainty index ranges from -0.21 (for the U.K.) to -0.39 (for the six countries aggregated factors weighted by the country's purchasing power parity adjusted GDP). ${ }^{19}$ The negative correlation is not surprising given that our factor is constructed from both oil price shocks and business cycle shocks, and periods of high uncertainty tend to be correlated with economic contractions and negative (or positive) oil price shocks. Similarly, a negative correlation is observed with the Jurado et al. (2015) macroeconomic uncertainty measure albeit it is more conservative and it ranges from -0.08 (for the U.K.) and -0.36 (for France). The Jurado et al. (2014) macroeconomic uncertainty measure is obtained from a large number of macroeconomic and firm specific time series. The index is not dependent on a specific macroeconomic theory and it is designed as the summary of unpredictable parts in many economic indicators. ${ }^{20}$

\footnotetext{
${ }^{18}$ This index is obtained from the following URL: www-personal.umich.edu/ lkilian/paperlinks.html.

${ }^{19}$ Economic Policy Uncertainty indices is a newspaper coverage of policy-related economic uncertainty constructed indices based on the methodology of Baker, Bloom and Davis (2016). These indices can be downloaded from WwW.policyuncertainty.com.

${ }^{20}$ The macroeconomic uncertainty index proposed by Jurado et al. (2016) is based on a common factor extracted from a panel containing the unforecastable component of a large number of monthly economic and financial
} 


\section{Conclusion}

Economic uncertainty plays a central role in investment and consumption decisions, and economic activity. It is no surprise that there has been a significant interest in seeking to understand the effect of uncertainty on macroeconomic performance. The literature has considered the direct transmission of uncertainty, whether it be oil price uncertainty or real economic uncertainty, on output growth. This paper proposes a novel method for studying the effect of macroeconomic uncertainty on economic activity via an indirect shock transmission channel which we model using a factor term that is driven by both oil price shocks and business cycle shocks. This factor approach is motivated by Henzel and Rengel's (2017) finding that two fundamental second-moment shocks largely explain the U.S. macroeconomic uncertainty measures. The first fundamental shock triggers uncertainty associated with demand-related variables like the aggregate production and capacity utilization, whilst the second fundamental shock affects uncertainty associated with supply-related variables such as oil and commodity prices. Using this modelling framework, we consider the impact of oil price shocks on real economic activity in the presence of direct and indirect transmission of shocks for a selected sample of oil exporting and importing countries.

Our results show that as well as the direct effect of oil price uncertainty and output growth uncertainty on real economic activity, the indirect effect of macroeconomic uncertainty stemming from business cycle and oil price shocks is statistically significant in the U.S. and France (Canada and Norway) for oil importing (exporting) countries. Allowing for the indirect transmission of

indicators. The authors compute macroeconomic uncertainty by aggregating the conditional volatility of the purely unpredictable component of the realization of each underlying macroeconomic time series. 
shocks in the model also increases the magnitude of and prolongs the impulse response of output growth to oil price shock. The effect of an oil price hike is found to be contractionary (expansionary) for oil importing (exporting) countries. Our findings are important from an empirical assessment of the effect of oil price shocks on real economic activity. Often empirical studies on this issue only consider the direct transmission of shocks through uncertainty and their effects on the economy. Our model estimates validate the indirect transmission of oil price shocks via macroeconomic uncertainty. The associated impulse response functions demonstrate that failing to account for both the direct and indirect transmission of shocks in the economy can yield erroneous findings on the impact of oil price shock on real economic activity. The derived factors which comprise oil price shocks and business cycle shocks display a moderate correlation with Kilian's real index and the economic policy uncertainty index. 


\section{References}

Aloui, R., Gupta, R. and Miller, S. (2016). Uncertainty and crude oil returns. Energy Economics, $55,92-100$.

Alquist, R. and Kilian, L. (2010). What do we learn from the price of crude oil futures? Journal of Applied Econometrics, 25, 539-573.

Angelini, E., Camba-Mendez, G., Giannone, D., Reichlin, L. and Rünstler, G. (2011). Short-term forecasts of euro area GDP growth. The Econometrics Journal, 14, 25-44.

Bachmann, R., Elstner, S. and Sims, E.R. (2013). Uncertainty and Economic Activity: Evidence from Business Survey Data. American Economic Journal: Macroeconomics, 5, 217-49.

Bai, J. and Wang, P. (2015). Identification and Bayesian Estimation of Dynamic Factor Models. Journal of Business and Economic Statistics, 33, 221-240.

Ball, L. (1992). Why does high inflation raise inflation uncertainty? Journal of Monetary Economics, 29, 371-388.

Baker, S.R., Bloom, N., and Davis, S.J. (2016). Measuring Economic Policy Uncertainty. The Quarterly Journal of Economics, 131, 1593-1636.

Baumeister, C. and Peersman G. (2013). The role of time-varying price elasticities in accounting for volatility changes in the crude oil market. Journal of Applied Econometrics, 28, 1087-1109

Bernanke, B.S., Gertler, M. and Watson, M. (1997). Systematic monetary policy and the effects of oil price shocks. Brookings Papers on Economic Activity, 1, 91-142.

Black, F. (1987). Business Cycles and Equilibrium. New York: Basil Blackwell.

Blackburn, K. (1999). Can stabilisation policy reduce long-run growth? Economic Journal, 109, 67-77.

Blanchard, O. and Gali, J. (2010). The macroeconomic effects of oil price shocks: Why are the 2000s so different from the 1970s? In J. Gal \& M. Gertler (Eds.), International dimensions of monetary policy (pp. 373-421). Chicago, IL: University of Chicago Press.

Bloom, N. (2009). The impact of uncertainty shocks. Econometrica, 77, 623-685.

Bloom, N., Bond, S., and Van Reenen, J. (2007). Uncertainty and investment dynamics. Review of Economic Studies 74, 391-415.

Bollerslev, T., Engle, R.F. and Wooldridge, J.M. (1988). A capital asset pricing model with time varying covariances. Journal of Political Economy, 96, 116-131. 
Born, B. and Pfeifer, J. (2014). Policy risk and business cycle. Journal of Monetary Economics, $68,68-85$.

Bredin, D., Elder, J. and Fountas, S. (2011). Oil volatility and the option value of waiting: An analysis of the G-7. Journal of Futures Markets, 31, 679-702.

Brunhes-Lesage, V. and Darné, O. (2012). Nowcasting the French index of industrial production: A comparison from bridge and factor models. Economic Modelling, 29, 2174-2182.

Bry, G. and Boschan, C. (1971). Cyclical Analysis of Time Series: Selected Procedures and Computer Programs, NBER, Technical Paper 20, New York: Columbia University Press for NBER.

Burns, A. F. and Mitchell, W. C. (1947). Measuring business cycles (reprinted). New York: National Bureau of Economic Research (NBER), Studies in Business Cycles 2.

Charles, A., Chua, C.L., Darné, O. and Suardi, S. (2020). On the Pernicious Effects of Oil Price Uncertainty on U.S. Real Economic Activities. Empirical Economics, forthcoming.

Charles, A. and Darné, O. (2014). Large shocks in the volatility of the Dow Jones Industrial average index: 1928-2013. Journal of Banking and Finance, 43, 188-199.

Chua, C.L., Suardi, S., and Tsiaplias, S. (2012). An impulse-response function for a VAR with multivariate GARCH-in-Mean that incorporates direct and indirect transmission of shocks. Economics Letters 117, 452-454.

Edelstein, P. and Kilian, P. (2007). The response of business fixed investment to energy price changes: a test of some hypotheses about the transmission of energy price shocks. B.E. Journal of Macroeconomics, 7, 1-41.

Elder, J. (2003). An impulse-response function for a vector autoregression with multivariate GARCH-in-mean. Economics Letters, 79, 21-26.

Elder, J. (2004). Another perspective on the effects of inflation volatility. Journal of Money, Credit and Banking, 36, 911-928.

Elder, J. and Serletis, A. (2009). Oil price uncertainty in Canada. Energy Economics, 31, 852856.

Ellen, S. and Zwinkels, R.C.J. (2010). Oil price dynamics: A behavioral finance approach with heterogeneous agents. Energy Economics, 32, 1427-1434.

Fountas, S., Karanasos, M., Kim, J. (2006). Inflation uncertainty, output growth uncertainty and macroeconomic performance. Oxford Bulletin of Economic and Statistics, 68, 319-343.

Friedman, M. (1977). Novel lecture: inflation and unemployment. Journal of Political Economy, $85,451-472$. 
Golinelli, R. and Parigi, G. (2007). The use of monthly indicators to forecast quarterly GDP in the short run: an application to the G7 countries. Journal of Forecasting, 26, 77-94.

Grier, K. and Perry, M. (2000). The effects of uncertainty on macroeconomic performance: Bivariate GARCH evidence. Journal of Applied Econometrics 15, 45-58.

Grier, K., Henry, O.T., Olekalns, N. and Shields, K. (2004). The asymmetric effects of uncertainty on inflation and output growth. Journal of Applied Econometrics, 19, 551-565.

Grilli, V. and Roubini, N. (1996). Liquidity models in open economies: Theory and empirical evidence. European Economic Review, 40, 847-859.

Guiso, L. and Parigi, G. (1999). Investment and demand uncertainty. Quarterly Journal of Economics, 114, 185-227.

Harding, D. and Pagan, A. (2003). A Comparison of two Business Cycle Dating Methods. Journal of Economic Dynamics and Control, 27, 1681-1690.

Henzel, S.R. and Rengel, M. (2017). Dimensions of Macroeconomic Uncertainty: A Common Factor Analysis. Economic Inquiry, 55, 843-877.

Herrera, A.M., Lagalo, L.G., and Wada, T. (2015). Asymmetries in the response of economic activity to oil price increases and decreases? Journal of International Money and Finance, 50, 108-133.

Jones, P. and Enders, W. (2016). The asymmetric effects of uncertainty on economic activity. Macroeconomic Dynamics, 20, 1219-1246.

Jurado, K.,Ludvigson S.C., and Ng, S. (2015). Measuring Uncertainty. American Economic Review, 105, 1177-1216.

Kellogg, R. (2014). The effect of uncertainty on investment: evidence from Texas oil drilling. American Economic Review, 104, 1698-1734.

Kilian, L. (2009). Not all oil price shocks are alike: disentangling demand and supply shocks in the crude oil market. American Economic Review, 99, 1053-1069.

Kilian, L. and Vigfusson, R.J. (2011). Are the response of the U.S. economy asymmetric in energy price increases and decreases? Quantitative Economics, 2, 419-453.

Kim, S. and Roubini, N. (2000). Exchange rate anomalies in the industrial countries: A solution with a structural VAR approach. Journal of Monetary Economics, 45, 561-586.

Kyritsis, E. and Serletis, A. (2019). Oil prices and the renewable energy sector. Energy Journal, 40, 1-27.

Laurent, S., Lecourt, C. and Palm, F.C. (2016). Testing for jumps in GARCH models: A robust approach. Computational Statistics and Data Analysis, 100, 383-400. 
Litzenberger, R.H. and Rabinowitz, N. (1995). Backwardation in oil futures markets: theory and empirical evidence. Journal of Finance, 50, 1517-1545.

Mitchell, James, Weale, Martin R., Wright, S. and Salazar, Eduardo L. (2005). An Indicator of Monthly GDP and an Early Estimate of Quarterly GDP Growth. Economic Journal, 115, 108129.

Mohn, K. and Misund, B. (2009). Investment and uncertainty in the international oil and gas industry. Energy Economics, 31, 240-248.

Ord, J., Koehler, A., and Snyder, R. (1997). Estimation and prediction for a class of dynamic nonlinear statistical models. Journal of the American Statistical Association, 92, 1621-1629.

Singleton, K. (2013). Investor flows and the 2008 boom/bust in oil prices. Management Science, 60, 300-318.

Snyder, R. (1985). Recursive estimation of dynamic linear statistical models. Journal of the Royal Statistical Society Series B, 47, 272-276.

Tsiaplias, S. and Chua, C.L. (2013). A multivariate GARCH model incorporating the direct and indirect transmission of shocks. Econometric Reviews, 32, 244-271.

Watson, M. W. (1994). Business-Cycle Durations and Postwar Stabilization of the U.S. Economy. The American Economic Review, 84, 24-46.

Yin, L. (2016). Does oil price respond to macroeconomic uncertainty? New evidence. Empirical Economics, 51, 921-938. 
Table 1 Data summary statistics

\begin{tabular}{|c|c|c|c|c|c|c|c|c|c|c|c|c|}
\hline & \multicolumn{2}{|c|}{ US } & \multicolumn{2}{|c|}{ Japan } & \multicolumn{2}{|c|}{ France } & \multicolumn{2}{|c|}{ Canada } & \multicolumn{2}{|c|}{ Norway } & \multicolumn{2}{|c|}{$\mathbf{U K}$} \\
\hline & $\Delta \mathrm{IPI}_{\mathrm{t}}$ & $\Delta \mathrm{Oil}_{\mathrm{t}}$ & $\Delta \mathrm{IPI}_{\mathrm{t}}$ & $\Delta \mathrm{Oil}_{\mathrm{t}}$ & $\Delta \mathrm{IPI}_{\mathrm{t}}$ & $\Delta \mathrm{Oil}_{\mathrm{t}}$ & $\Delta \mathrm{IPI}_{\mathrm{t}}$ & $\Delta \mathrm{Oil}_{\mathrm{t}}$ & $\Delta \mathrm{IPI}_{\mathrm{t}}$ & $\Delta \mathrm{Oil}_{\mathrm{t}}$ & $\Delta \mathrm{IPI}_{\mathrm{t}}$ & $\Delta \mathrm{Oil}_{\mathrm{t}}$ \\
\hline Mean & 0.0017 & 0.0002 & 0.0003 & -0.0016 & 0.0001 & -0.0009 & 0.0011 & 0.0002 & 0.0010 & 0.0001 & 0.0002 & -0.0002 \\
\hline Std Dev & 0.0062 & 0.0855 & 0.0187 & 0.0899 & 0.0134 & 0.0849 & 0.0093 & 0.0875 & 0.0414 & 0.0864 & 0.0098 & 0.0903 \\
\hline $\mathrm{ADF}$ & $-5.05 * * *$ & $-8.58 * * *$ & $-11.61 * * *$ & $-8.74 * * *$ & $-6.19 * * *$ & $-9.75 * * *$ & $-7.68 * * *$ & $-9.31 * * *$ & $-15.99 * * *$ & $-9.52 * * *$ & $-5.73 * * *$ & $-9.33 * * *$ \\
\hline $\mathrm{ARCH}(6)$ & $52.59 * * *$ & $88.79 * * *$ & $16.38 * * *$ & $78.27 * * *$ & $26.17 * * *$ & $60.52 * * *$ & $24.91 * * *$ & $85.14 * * *$ & $123.19 * * *$ & $72.77 * * *$ & $25.92 * * *$ & $68.36 * * *$ \\
\hline Skewness & $-1.67 * * *$ & $-0.68 * * *$ & $-2.83 * * *$ & $-0.94 * * *$ & -0.01 & $-0.72 * * *$ & -0.15 & $-0.43 * * *$ & $-0.74 * * *$ & $-0.47 * * *$ & $-0.67 * * *$ & $-0.44 * * *$ \\
\hline Kurtosis & $9.42 * * *$ & $2.93 * * *$ & $22.33 * * *$ & $3.82 * * *$ & $1.05 * * *$ & $2.79 * * *$ & $0.67 * * *$ & $2.45^{* * *}$ & $33.61 * * *$ & $2.33^{* * *}$ & $2.74 * * *$ & $1.71 * * *$ \\
\hline $\begin{array}{l}\text { Jarque- } \\
\text { Bera }\end{array}$ & $1529.80 * * *$ & $160.90 * * *$ & $8119.95 * * *$ & $277.77 * * *$ & $17.19 * * *$ & $151.39 * * *$ & $8.40 * *$ & $103.71 * * *$ & $17315.51 * * *$ & $96.74 * * *$ & $143.21 * * *$ & $57.33 * * *$ \\
\hline
\end{tabular}

Note: $\mathrm{IPI}_{t}$ denotes industrial production index while $0 \mathrm{il}_{t}$ denotes oil price. Annualized output growth is denoted by $\Delta \mathrm{IPI}_{t}=1200 \times \ln \left(\mathrm{IPI}_{t} / \mathrm{IPI}_{t-1}\right)$

while annualized first difference in oil price is given by $\Delta \mathrm{Oil}_{t}=1200 \times \ln \left(\mathrm{Oil}_{t} / \mathrm{Oil} \mathrm{l}_{t-1}\right)$. ADF is the Augmented Dickey-Fuller test statistic for unit root with critical values $-3.98(10 \%),-3.42(5 \%),-3.13(1 \%)$. ARCH(6) is the LM test for sixth order ARCH derived from the squared residuals of the univariate autoregression under the null of no ARCH effect up to lag order 6 . The LM test is distributed as a $\chi_{(6)}{ }^{2}$. *** denotes significance at the $1 \%$ level. 
Table 2 Outliers of $\Delta I P I_{t}$ and $\Delta O i l_{t}$ based on the Laurent et al. (2016) test

\begin{tabular}{|l|l|c|l|}
\hline Series & Date & Test-stat & Events \\
\hline US oil & 1986.02 & 3.84 & Iran-Iraq war \\
\hline & 1990.08 & 3.12 & Invasion of Kuwait by Iraq \\
\hline & 2008.10 & 3.15 & The global financial recession \\
\hline & 2014.12 & 3.16 & High US production \\
\hline US IPI & 2008.09 & 4.64 & The global financial recession \\
\hline Canada oil & 1990.08 & 3.52 & Invasion of Kuwait by Iraq \\
\hline Canada IPI & & & \\
\hline & & & \\
\hline Japan oil & 1986.02 & 4.33 & Iran-Iraq war \\
\hline & 1990.08 & 3.17 & Invasion of Kuwait by Iraq \\
\hline & 2008.10 & 3.13 & The global financial recession \\
\hline Japan IPI & 2008.11 & 4.34 & The global financial recession \\
\hline & 2011.03 & 6.92 & 2011 Tōhoku earthquake \& Fukushima nuclear disaster \\
\hline & 2011.05 & 3.25 & 2011 Tōhoku earthquake \& Fukushima nuclear disaster \\
\hline & & & \\
\hline Norway oil & 1986.02 & 3.17 & Iran-Iraq war \\
\hline & 1990.08 & 3.86 & Invasion of Kuwait by Iraq \\
\hline $\begin{array}{l}\text { Norway } \\
\text { IPI }\end{array}$ & 1986.04 & 11.61 & Iran-Iraq war \\
\hline & & & \\
\hline UK oil & 1990.08 & 3.76 & Invasion of Kuwait by Iraq \\
\hline UK IPI & 2002.06 & 4.72 & $\begin{array}{l}\text { Reorganization of bank holidays for the Queen's Golden } \\
\text { Jubilee }\end{array}$ \\
\hline France oil & 1986.02 & 3.86 & Iran-Iraq war \\
\hline France IPI & & & \\
\hline Non & & & \\
\hline
\end{tabular}

Note: The test statistic is the Laurent et al. (2016) test. The Gumbel critical value at the 5\% level is 3.118 for $\mathrm{T}=366$. 
Table 3 Model Coefficient Estimates

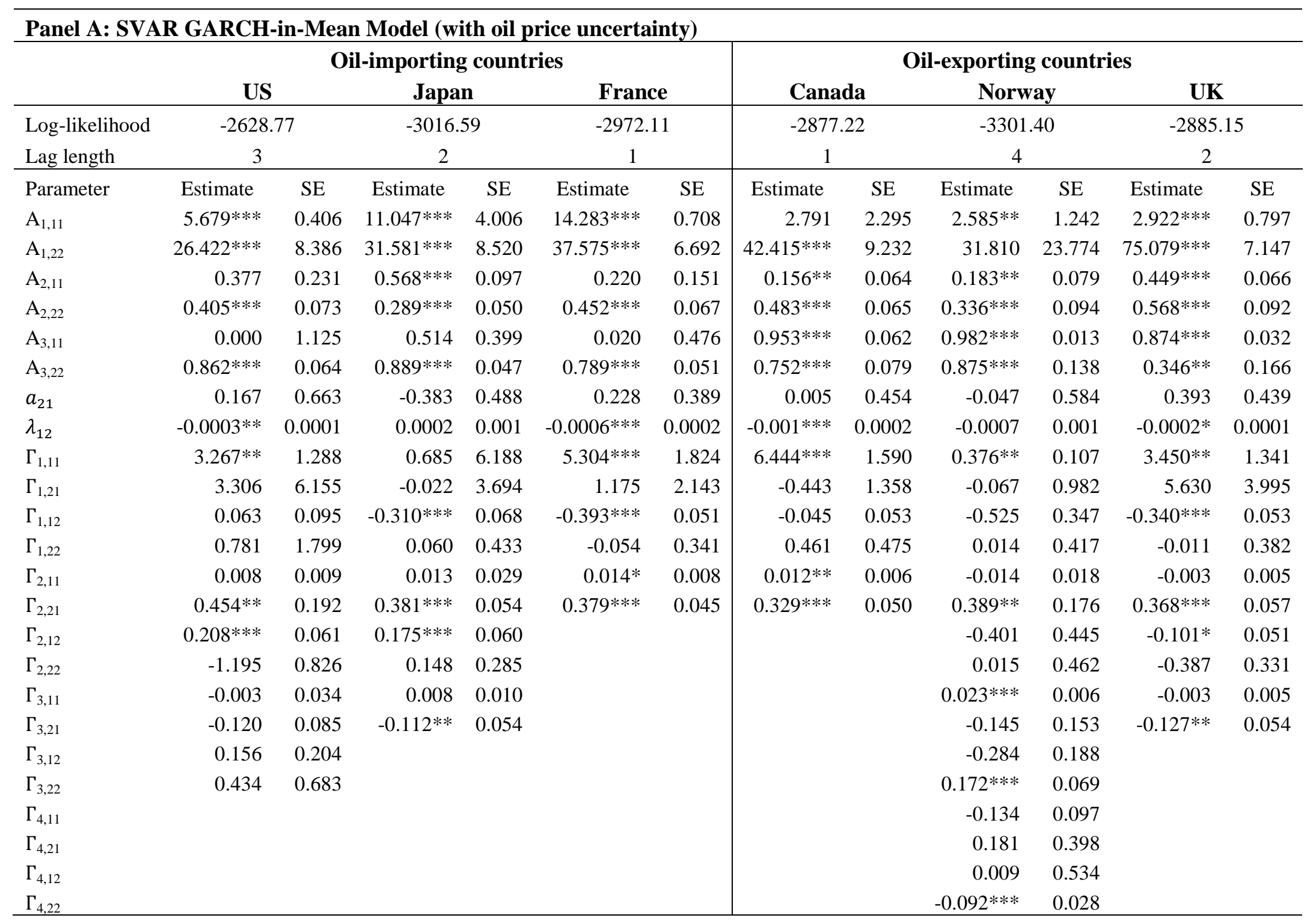




\begin{tabular}{|c|c|c|c|c|c|c|c|c|c|c|c|c|}
\hline \multicolumn{13}{|c|}{ Panel B: SFVAR GARCH-in-Mean Model (with oil price uncertainty) } \\
\hline & \multicolumn{6}{|c|}{ Oil-importing countries } & \multicolumn{6}{|c|}{ Oil-exporting countries } \\
\hline & \multicolumn{2}{|c|}{$\mathbf{U S}$} & \multicolumn{2}{|c|}{ Japan } & \multicolumn{2}{|c|}{ France } & \multicolumn{2}{|c|}{ Canada } & \multicolumn{2}{|c|}{ Norway } & \multicolumn{2}{|c|}{$\mathbf{U K}$} \\
\hline Lag length & \multicolumn{2}{|c|}{2} & \multicolumn{2}{|l|}{2} & \multicolumn{2}{|l|}{2} & \multicolumn{2}{|c|}{3} & \multicolumn{2}{|c|}{1} & \multicolumn{2}{|l|}{1} \\
\hline Parameter & Estimate & SE & Estimate & SE & Estimate & $\mathrm{SE}$ & Estimate & $\mathrm{SE}$ & Estimate & SE & Estimate & $\mathrm{SE}$ \\
\hline$\rho$ & $0.239^{*}$ & 0.137 & 0.303 & 0.774 & $0.603 * * *$ & 0.047 & 0.298 & 0.235 & $0.345^{* * *}$ & 0.055 & $0.275 * * *$ & 0.062 \\
\hline$g_{1}$ & 0.326 & 0.265 & 1.062 & 5.391 & $0.113 * * *$ & 0.043 & -0.284 & 0.321 & 0.532 & 0.662 & -0.236 & 0.181 \\
\hline$g_{2}$ & $0.791 * * *$ & 0.198 & 1.146 & 2.631 & $0.029 *$ & 0.018 & $1.159 * * *$ & 0.346 & $2.256 * * *$ & 0.506 & 0.218 & 0.179 \\
\hline$b$ & -0.516 & 0.336 & -1.080 & 6.835 & $-0.938 * * *$ & 0.053 & 0.174 & 0.415 & -0.391 & 0.288 & $3.438 * * *$ & 1.194 \\
\hline $\mathrm{A}_{1,11}$ & $5.670 * * *$ & 0.314 & 7.594 & 44.779 & $1.308 * * *$ & 0.112 & $9.803 * * *$ & 0.452 & $28.360 * * *$ & 3.162 & $3.631 * *$ & 1.515 \\
\hline $\mathrm{A}_{1,22}$ & $26.927 * *$ & 10.710 & $85.709 * * *$ & 19.931 & $1.773 * * *$ & 0.252 & $58.207 * * *$ & 11.648 & $26.498 * * *$ & 9.046 & $79.110 * * *$ & 8.464 \\
\hline $\mathrm{A}_{2,11}$ & $0.363 * * *$ & 0.130 & 0.454 & 0.788 & $0.252 * * *$ & 0.009 & $0.302 * * *$ & 0.100 & $0.483 * * *$ & 0.085 & $0.414^{* * *} *$ & 0.067 \\
\hline $\mathrm{A}_{2,22}$ & $0.395 * * *$ & 0.077 & 0.254 & 4.078 & $0.249 * * *$ & 0.005 & $0.586 * * *$ & 0.078 & $0.321 * * *$ & 0.053 & $0.532 * * *$ & 0.079 \\
\hline $\mathrm{A}_{3,22}$ & $0.863^{* * *}$ & 0.076 & $0.815 * * *$ & 0.167 & $0.968 * * *$ & 0.001 & $0.532 * * *$ & 0.177 & $0.905 * * *$ & 0.039 & $0.677 * * *$ & 0.219 \\
\hline$a_{21}$ & 0.330 & 0.428 & -0.443 & 3.621 & $2.329 * * *$ & 0.342 & 0.151 & 0.599 & -0.266 & 0.454 & 0.525 & 0.406 \\
\hline$\lambda_{12}$ & $0.0004 * *$ & 0.0002 & -0.0007 & 0.003 & $-0.0005^{* *}$ & 0.0002 & $-0.0003 * *$ & 0.0001 & -0.0009 & 0.004 & -0.0003 & 0.004 \\
\hline$\Gamma_{1,11}$ & -0.540 & 0.461 & -0.859 & 1.785 & $-0.642 * * *$ & 0.075 & 0.066 & 0.621 & -0.387 & 0.460 & -0.202 & 0.125 \\
\hline$\Gamma_{1,21}$ & $1.251 * *$ & 0.634 & 0.574 & 6.503 & $-0.895^{* * *}$ & 0.207 & 0.473 & 0.504 & 0.222 & 0.179 & 0.377 & 0.384 \\
\hline$\Gamma_{1,12}$ & $-0.783 * * *$ & 0.199 & -1.137 & 2.682 & -0.019 & 0.020 & $-1.143 * * *$ & 0.345 & $-2.239 * * *$ & 0.507 & -0.219 & 0.176 \\
\hline$\Gamma_{1,22}$ & $0.833 * * *$ & 0.225 & 1.638 & 5.545 & $0.500 * * *$ & 0.035 & 0.203 & 0.495 & $1.213 *$ & 0.715 & -0.433 & 0.422 \\
\hline$\Gamma_{2,11}$ & 0.820 & 0.707 & -0.379 & 1.047 & $-0.294 * * *$ & 0.048 & 0.564 & 0.721 & & & & \\
\hline$\Gamma_{2,21}$ & $-0.796^{*}$ & 0.453 & 0.419 & 2.863 & $-0.921 * * *$ & 0.138 & 0.269 & 0.473 & & & & \\
\hline$\Gamma_{2,12}$ & 0.145 & 0.131 & 0.116 & 0.815 & 0.001 & 0.009 & 0.108 & 0.277 & & & & \\
\hline$\Gamma_{2,22}$ & -0.125 & 0.083 & -0.175 & 0.363 & $-0.102 * * *$ & 0.033 & $-0.151 * *$ & 0.072 & & & & \\
\hline$\Gamma_{3,11}$ & & & & & & & 0.600 & 0.619 & & & & \\
\hline$\Gamma_{3,21}$ & & & & & & & 0.002 & 0.212 & & & & \\
\hline
\end{tabular}




\begin{tabular}{|c|c|c|c|c|c|c|c|c|c|c|c|c|}
\hline \multicolumn{13}{|c|}{ Panel C: SFVAR GARCH-in-Mean Model (with real economic uncertainty and oil price uncertainty) } \\
\hline & \multicolumn{6}{|c|}{ Oil-importing countries } & \multicolumn{6}{|c|}{ Oil-exporting countries } \\
\hline & \multicolumn{2}{|c|}{ US } & \multicolumn{2}{|c|}{ Japan } & \multicolumn{2}{|c|}{ France } & \multicolumn{2}{|c|}{ Canada } & \multicolumn{2}{|c|}{ Norway } & \multicolumn{2}{|c|}{ UK } \\
\hline Log-likelihood & \multicolumn{2}{|c|}{-2743.37} & \multicolumn{2}{|c|}{-2994.8} & \multicolumn{2}{|c|}{-2959.32} & \multicolumn{2}{|c|}{-2856.18} & \multicolumn{2}{|c|}{-3305.36} & \multicolumn{2}{|c|}{-2878.23} \\
\hline Lag length & \multicolumn{2}{|c|}{4} & \multicolumn{2}{|c|}{3} & \multicolumn{2}{|c|}{2} & \multicolumn{2}{|c|}{3} & \multicolumn{2}{|c|}{1} & \multicolumn{2}{|c|}{1} \\
\hline Parameter & Estimate & $\mathrm{SE}$ & Estimate & SE & Estimate & $\mathrm{SE}$ & Estimate & SE & Estimate & SE & Estimate & SE \\
\hline$\rho$ & $0.949 * * *$ & 0.005 & 0.002 & 0.264 & 0.162 & 0.313 & $0.120^{*}$ & 0.065 & $0.898 * * *$ & 0.046 & 0.003 & 0.346 \\
\hline$g_{1}$ & $0.158 * * *$ & 0.010 & 0.526 & 0.725 & 0.122 & 0.540 & $-2.733 * * *$ & 0.173 & -0.019 & 0.029 & -0.191 & 0.188 \\
\hline$g_{2}$ & $-0.003 * *$ & 0.001 & $1.338^{*}$ & 0.753 & 0.795 & 0.649 & $1.553 * * *$ & 0.049 & -0.014 & 0.027 & 0.018 & 0.030 \\
\hline$b$ & $-0.750 * * *$ & 0.215 & -0.579 & 0.770 & -0.323 & 1.597 & $1.377 * * *$ & 0.047 & $1.993 * * *$ & 0.473 & 2.152 & 2.457 \\
\hline $\mathrm{A}_{1,11}$ & $0.259 * * *$ & 0.003 & $9.025 * * *$ & 1.564 & $13.766^{* * *} *$ & 2.078 & $9.615^{* * *}$ & 0.468 & $20.490 * * *$ & 5.316 & $3.795^{* *}$ & 1.657 \\
\hline $\mathrm{A}_{1,22}$ & $6.120 * * *$ & 0.087 & $30.166^{* * *} *$ & 10.212 & $-36.095 * * *$ & 11.460 & $30.947 * * *$ & 3.669 & 37.750 & 38.931 & $65.031 * * *$ & 8.614 \\
\hline $\mathrm{A}_{2,11}$ & $0.444 * * *$ & 0.002 & $0.518 * * *$ & 0.076 & $0.352 * *$ & 0.138 & $0.320 * * *$ & 0.081 & $0.593 * * *$ & 0.121 & $0.390 * * *$ & 0.061 \\
\hline $\mathrm{A}_{2,22}$ & $0.454 * * *$ & 0.006 & $0.272 * * *$ & 0.061 & $0.436 * * *$ & 0.103 & $0.437 * * *$ & 0.060 & $0.326 * *$ & 0.146 & $0.536 * * *$ & 0.067 \\
\hline $\mathrm{A}_{3,11}$ & $0.796 * * *$ & 0.106 & $0.649 * * *$ & 0.116 & $0.601 * * *$ & 0.186 & 0.095 & 0.345 & $0.638 * * *$ & 0.105 & $0.853 * * *$ & 0.082 \\
\hline $\mathrm{A}_{3,22}$ & $0.890 * * *$ & 0.103 & $0.899 * * *$ & 0.058 & $0.804 * * *$ & 0.169 & $0.840 * * *$ & 0.033 & $0.850 * * *$ & 0.269 & $0.534 * * *$ & 0.135 \\
\hline$a_{21}$ & $1.478 * * *$ & 0.339 & -0.527 & 0.392 & 0.231 & 0.358 & $0.348 * * *$ & 0.106 & -0.061 & 0.631 & 0.167 & 0.478 \\
\hline$\lambda_{11}$ & $0.064 * * *$ & 0.002 & 0.001 & 0.002 & -0.001 & 0.002 & 0.083 & 0.052 & 0.008 & 0.006 & -0.005 & 0.009 \\
\hline$\lambda_{12}$ & $-0.001 * * *$ & 0.0001 & -4.340 & 4.097 & 4.950 & 3.132 & $-0.001 * * *$ & 0.0002 & -0.001 & 0.001 & $-0.0002 * *$ & 0.0001 \\
\hline$\lambda_{21}$ & $0.326^{* * *}$ & 0.007 & -0.407 & 0.825 & 0.086 & 3.721 & 0.145 & 0.104 & 0.002 & 0.011 & 0.060 & 0.086 \\
\hline$\lambda_{22}$ & $-0.003 * * *$ & 0.000 & -0.137 & 0.833 & -0.757 & 0.609 & $-0.001 * * *$ & 0.0002 & 0.004 & 0.004 & $0.004 * * *$ & 0.001 \\
\hline$\Gamma_{1,11}$ & -0.020 & 0.020 & 1.208 & 0.655 & $0.670 * * *$ & 0.071 & $2.170 * * *$ & 0.141 & $-0.332 * * *$ & 0.058 & -0.146 & 0.189 \\
\hline$\Gamma_{1,21}$ & $1.637 * * *$ & 0.263 & $0.229 * * *$ & 0.643 & -0.244 & 0.359 & $3.317 * * *$ & 0.104 & 0.060 & 0.250 & 0.556 & 0.560 \\
\hline$\Gamma_{1,12}$ & -0.001 & 0.004 & $0.060 *$ & 0.307 & $-0.124 * * *$ & 0.058 & $-1.538 * * *$ & 0.049 & 0.015 & 0.071 & -0.019 & 0.027 \\
\hline$\Gamma_{1,22}$ & $0.354 * * *$ & 0.016 & 0.580 & 0.468 & 0.204 & 0.399 & $-1.716^{* * *}$ & 0.076 & $0.364 * *$ & 0.173 & $0.342 * *$ & 0.108 \\
\hline$\Gamma_{2,11}$ & 0.085 & 0.062 & -0.434 & 0.284 & $-0.123 * * *$ & 0.025 & $0.802 *$ & 0.423 & & & & \\
\hline$\Gamma_{2,21}$ & $0.855^{* * *}$ & 0.068 & 0.409 & 0.507 & $-0.150 * * *$ & 0.030 & $1.260 * * *$ & 0.432 & & & & \\
\hline$\Gamma_{2,12}$ & 0.005 & 0.004 & -0.332 & 0.433 & 0.018 & 0.020 & $0.415 * * *$ & 0.057 & & & & \\
\hline$\Gamma_{2,22}$ & 0.041 & 0.027 & -0.118 & 0.222 & $-0.110 * *$ & 0.051 & $0.397 * * *$ & 0.070 & & & & \\
\hline$\Gamma_{3,11}$ & $0.133^{* * *} *$ & 0.030 & $0.059 * * *$ & 0.007 & & & $0.552 * * *$ & 0.187 & & & & \\
\hline$\Gamma_{3,21}$ & $0.277 * * *$ & 0.081 & $-0.021 * *$ & 0.010 & & & $0.806 * * *$ & 0.282 & & & & \\
\hline
\end{tabular}




\begin{tabular}{rrrrr|ll}
$\Gamma_{3,12}$ & $-0.012^{* * *}$ & 0.004 & $0.023 * * *$ & 0.007 & $-0.201 * * *$ & 0.036 \\
$\Gamma_{3,22}$ & $-0.108 * * *$ & 0.029 & -0.060 & 0.120 & $-0.258^{* * *}$ & 0.057 \\
$\Gamma_{4,11}$ & $-0.086^{* * *}$ & 0.017 & & & & \\
$\Gamma_{4,21}$ & $-1.893^{* * *}$ & 0.119 & & & & \\
$\Gamma_{4,12}$ & -0.004 & 0.006 & & & & \\
$\Gamma_{4,22}$ & $-0.067 * * *$ & 0.023 & & & & \\
\hline
\end{tabular}

Note: Panel A shows the results for the SVAR GARCH-in-Mean model while Panel B shows the results for the model which incorporates the latent factor. In both panels only oil price uncertainty is considered. Panel C shows the results for the SFVAR GARCH-in-Mean model which incorporates both real and oil price uncertainty. The lag length indicates the optimal lag length of the VAR specification based on the AIC. SE is robust standard error. $* * * * *$ and $*$ denote significance at the $1 \%, 5 \%$ and $10 \%$ level, respectively. 
Table 4: Information criteria and log likelihood estimates

\begin{tabular}{|c|c|c|c|c|c|c|}
\hline & \multicolumn{3}{|c|}{ Oil importing countries } & \multicolumn{3}{|c|}{ Oil exporting countries } \\
\hline & \multicolumn{3}{|c|}{ US } & \multicolumn{3}{|c|}{ Canada } \\
\hline Log likelihood function & -2628.8 & -2628.0 & -2743.4 & -2877.2 & -2855.5 & -2856.2 \\
\hline AIC & 5299.5 & 5298.1 & 5552.7 & 5780.4 & 5761.0 & 5770.4 \\
\hline \multirow[t]{2}{*}{$\mathrm{SIC}$} & 5377.8 & 5376.4 & 5670.1 & 5854.2 & 5828.9 & 5872.8 \\
\hline & \multicolumn{3}{|c|}{ Japan } & \multicolumn{3}{|c|}{ Norway } \\
\hline Log likelihood function & -3016.6 & -3002.9 & -2994.8 & -3301.4 & -3301.6 & -3305.4 \\
\hline AIC & 6067.2 & 6047.8 & 6047.6 & 6628.8 & 6637.1 & 6652.7 \\
\hline \multirow[t]{2}{*}{ SIC } & 6130.6 & 6126.1 & 6150.0 & 6809.0 & 6700.5 & 6725.3 \\
\hline & \multicolumn{3}{|c|}{ France } & \multicolumn{3}{|c|}{ UK } \\
\hline Log likelihood function & -2972.1 & -3000.4 & -2959.3 & -2885.1 & -2882.2 & -2878.4 \\
\hline AIC & 5970.2 & 6042.8 & 5968.6 & 5804.3 & 5798.5 & 5798.8 \\
\hline SIC & 6018.7 & 6121.1 & 6056.1 & 5867.7 & 5861.9 & 5871.4 \\
\hline
\end{tabular}


Table 5: Symmetry test results of the response of real GDP growth to oil price increases and decreases

\begin{tabular}{|c|c|c|c|c|c|c|c|c|c|c|c|c|}
\hline & \multicolumn{6}{|c|}{ Oil-importing countries } & \multicolumn{6}{|c|}{ Oil-exporting countries } \\
\hline & \multicolumn{2}{|c|}{ US } & \multicolumn{2}{|c|}{ Japan } & \multicolumn{2}{|c|}{ France } & \multicolumn{2}{|c|}{ Canada } & \multicolumn{2}{|c|}{ Norway } & \multicolumn{2}{|c|}{ United Kingdom } \\
\hline$h$ & $\begin{array}{c}1 \text { Std. } \\
\text { Deviation } \\
\text { Shock }\end{array}$ & $\begin{array}{c}2 \text { Std. } \\
\text { Deviation } \\
\text { Shock }\end{array}$ & $\begin{array}{c}1 \text { Std. } \\
\text { Deviation } \\
\text { Shock }\end{array}$ & $\begin{array}{c}2 \text { Std. } \\
\text { Deviation } \\
\text { Shock }\end{array}$ & $\begin{array}{c}1 \text { Std. } \\
\text { Deviation } \\
\text { Shock }\end{array}$ & $\begin{array}{l}2 \text { Std. } \\
\text { Deviation } \\
\text { Shock }\end{array}$ & $\begin{array}{c}1 \text { Std. } \\
\text { Deviation } \\
\text { Shock }\end{array}$ & $\begin{array}{c}2 \text { Std. } \\
\text { Deviation } \\
\text { Shock }\end{array}$ & $\begin{array}{c}1 \text { Std. } \\
\text { Deviation } \\
\text { Shock }\end{array}$ & $\begin{array}{c}2 \text { Std. } \\
\text { Deviation } \\
\text { Shock }\end{array}$ & $\begin{array}{c}1 \text { Std. } \\
\text { Deviation } \\
\text { Shock }\end{array}$ & $\begin{array}{c}2 \text { Std. } \\
\text { Deviation } \\
\text { Shock }\end{array}$ \\
\hline 0 & 0.79 & 0.92 & 0.48 & 0.16 & 0.31 & 0.86 & 0.05 & 0.09 & 0.00 & 0.00 & 0.04 & 0.09 \\
\hline 1 & 0.00 & 0.00 & 0.00 & 0.00 & 0.00 & 0.00 & 0.00 & 0.00 & 0.02 & 0.00 & 0.00 & 0.00 \\
\hline 2 & 0.00 & 0.00 & 0.00 & 0.00 & 0.00 & 0.00 & 0.00 & 0.00 & 0.03 & 0.38 & 0.00 & 0.00 \\
\hline 3 & 0.00 & 0.00 & 0.00 & 0.00 & 0.02 & 0.04 & 0.00 & 0.00 & 0.00 & 0.00 & 0.00 & 0.00 \\
\hline 4 & 1.00 & 0.04 & 0.03 & 0.00 & 0.00 & 0.00 & 0.00 & 0.00 & 0.00 & 0.00 & 0.00 & 0.00 \\
\hline 5 & 0.97 & 0.02 & 0.00 & 0.00 & 0.00 & 0.00 & 0.00 & 0.00 & 0.00 & 0.02 & 0.05 & 0.01 \\
\hline 6 & 1.00 & 0.00 & 0.00 & 0.00 & 1.00 & 0.00 & 0.00 & 0.00 & 0.00 & 0.00 & 0.00 & 0.00 \\
\hline 7 & 0.63 & 0.00 & 1.00 & 0.07 & 0.82 & 0.00 & 0.16 & 0.03 & 0.98 & 0.00 & 0.05 & 0.02 \\
\hline 8 & 0.22 & 0.00 & 0.42 & 0.00 & 0.17 & 0.00 & 1.00 & 0.00 & 1.00 & 0.00 & 0.99 & 0.00 \\
\hline 9 & 0.19 & 0.00 & 1.00 & 0.00 & 1.00 & 0.06 & 0.30 & 0.04 & 1.00 & 0.00 & 0.38 & 0.00 \\
\hline 10 & 0.95 & 0.00 & 0.98 & 0.00 & 0.34 & 0.00 & 1.00 & 0.00 & 1.00 & 0.00 & 0.63 & 0.00 \\
\hline 11 & 1.00 & 0.00 & 0.99 & 0.00 & 1.00 & 0.00 & 1.00 & 0.02 & 0.97 & 0.00 & 0.27 & 0.00 \\
\hline 12 & 1.00 & 0.00 & 1.00 & 0.00 & 1.00 & 0.00 & 1.00 & 0.07 & 0.97 & 0.00 & 1.00 & 0.00 \\
\hline
\end{tabular}

Note: Results are p-values of the test statistic under the null hypothesis that $I_{z}(h, \delta)=-I_{z}(h,-\delta)$ where $\mathrm{h}=0,1,2, \ldots, 12$ and $\delta$ is the size of the shock measured as a standard deviation of oil price shock. The test statistic follows a $\chi^{2}$ distribution with $\mathrm{H}+1$ degree of freedom. The results are based on 10,000 simulations of model (6) with 100 histories of $z$ and $x$ series. 
Table 6: Correlation matrix of six countries' common factors

\begin{tabular}{ccccccc}
\hline & US & Japan & France & Canada & Norway & UK \\
\hline US & & & & & & \\
Japan & 0.92 & & & & & \\
France & 0.49 & 0.57 & & & & \\
Canada & 0.91 & 0.89 & 0.52 & & & \\
Norway & 0.89 & 0.90 & 0.54 & 0.95 & & \\
UK & 0.89 & 0.88 & 0.54 & 0.95 & 0.95 & \\
\hline
\end{tabular}

Table 7: Average duration of contractions and expansions of the six countries' common factors

\begin{tabular}{lcccccc}
\hline Average duration: & US & Japan & France & Canada & Norway & UK \\
\hline Contractions & 4.57 & 4.50 & 8.23 & 4.62 & 4.26 & 4.97 \\
Expansions & 5.86 & 5.80 & 8.36 & 6.12 & 6.47 & 5.31 \\
\hline
\end{tabular}


Table 8: Correlation of smoothed country's factor with various uncertainty measures

\begin{tabular}{|c|c|c|c|c|c|c|c|c|c|}
\hline \multicolumn{10}{|c|}{ Economic Policy Uncertainty } \\
\hline & Global & $\begin{array}{l}\text { United } \\
\text { States }\end{array}$ & Japan & France & Canada & Europe & $\begin{array}{c}\text { United } \\
\text { Kingdom }\end{array}$ & $\begin{array}{c}\text { Macro } \\
\text { Uncertainty }\end{array}$ & $\begin{array}{c}\text { Kilian's } \\
\text { Real Index }\end{array}$ \\
\hline Weighted & & & & & & & & & \\
\hline Average & -0.39 & & & & & & & -0.16 & 0.33 \\
\hline United States & & -0.27 & & & & & & -0.11 & 0.31 \\
\hline Japan & & & -0.26 & & & & & -0.22 & 0.34 \\
\hline France & & & & -0.22 & & -0.29 & & -0.36 & 0.25 \\
\hline Canada & & & & & -0.25 & & & -0.15 & 0.30 \\
\hline Norway & & & & & & -0.17 & & -0.19 & 0.32 \\
\hline United Kingdom & & & & & & -0.18 & -0.21 & -0.08 & 0.35 \\
\hline
\end{tabular}

Note: Economic policy uncertainty measure is newspaper coverage of policy-related economic uncertainty constructed indices based on the methodology of Baker, Bloom and Davis (2016). Macro uncertainty is the one-month ahead uncertainty measure based on the methodology of Jurado, Ludvigson and $\mathrm{Ng}$ (2015). This index quantifies macroeconomic uncertainty from a large number of macroeconomic and firm specific time series. It is not dependent on a specific macroeconomic theory, and is designed as the summary of unpredictable parts in many economic indicators. Kilian's Real Index is a proxy for global economic activities related to commodities computed from cargo ship freight rates (Kilian, 2009). The weighted average of the six country factors is obtained using weights, which are computed from the respective countries' GDP at purchasing power parity level. 


\section{Figure 1 Flow chart diagram depicting the effects of uncertainty on real economic activity}

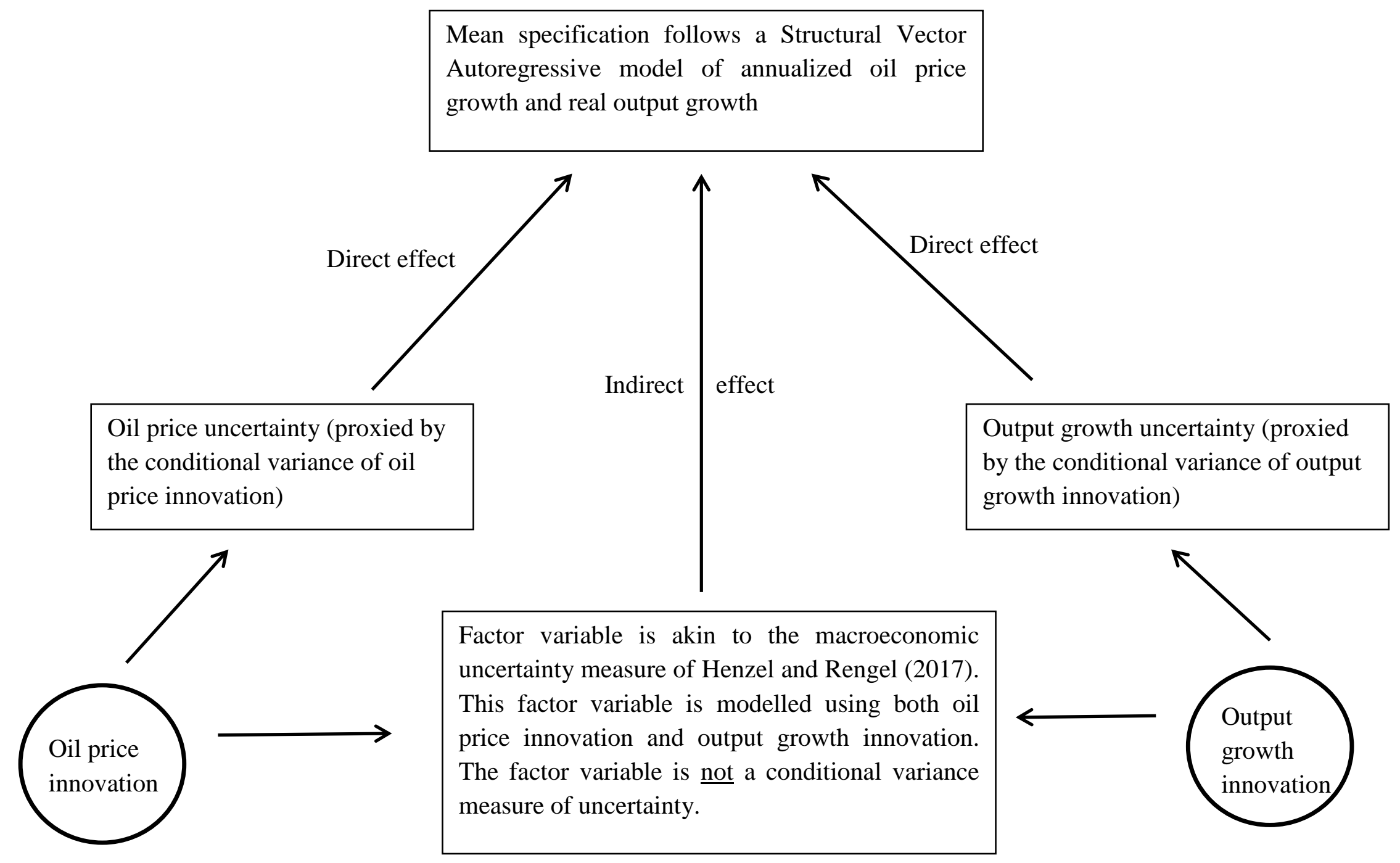




\section{Figure 2 Data plots of output growth and annualized change in oil prices}
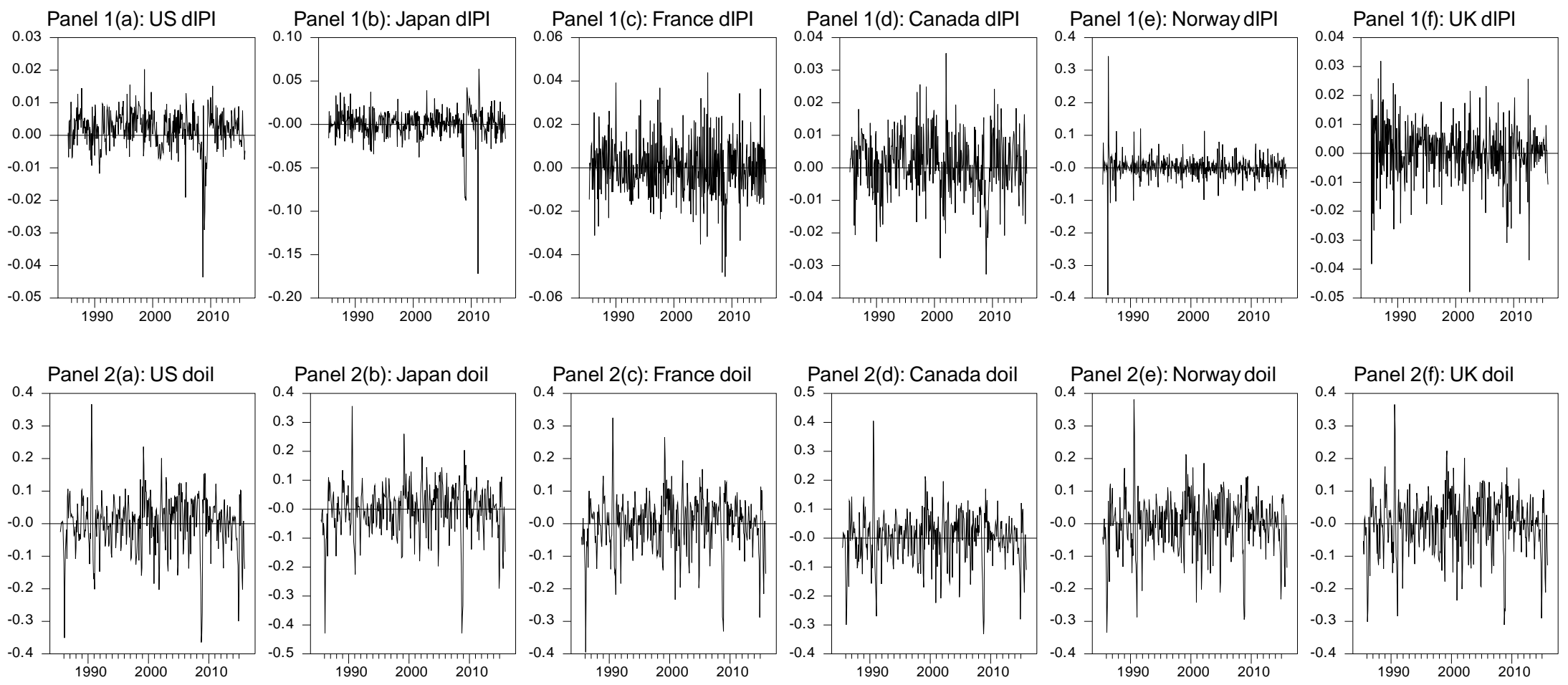

Note: 'dIPI' denotes utput growth rate which is the annualized first difference of the logarithm of IPI. 'doil' denotes price changes in the annualized first difference of the logarithm of oil prices. The first row indicates the growth rate of oil importing countries (US, Japan and France) followed by those of oil exporting countries (Canada, Norway and UK). The second row shows the corresponding country's annualized change in oil price. 


\section{Figure 3: Impulse responses of real economic activity to a positive oil price shock for the six countries}

\section{Oil importing countries}
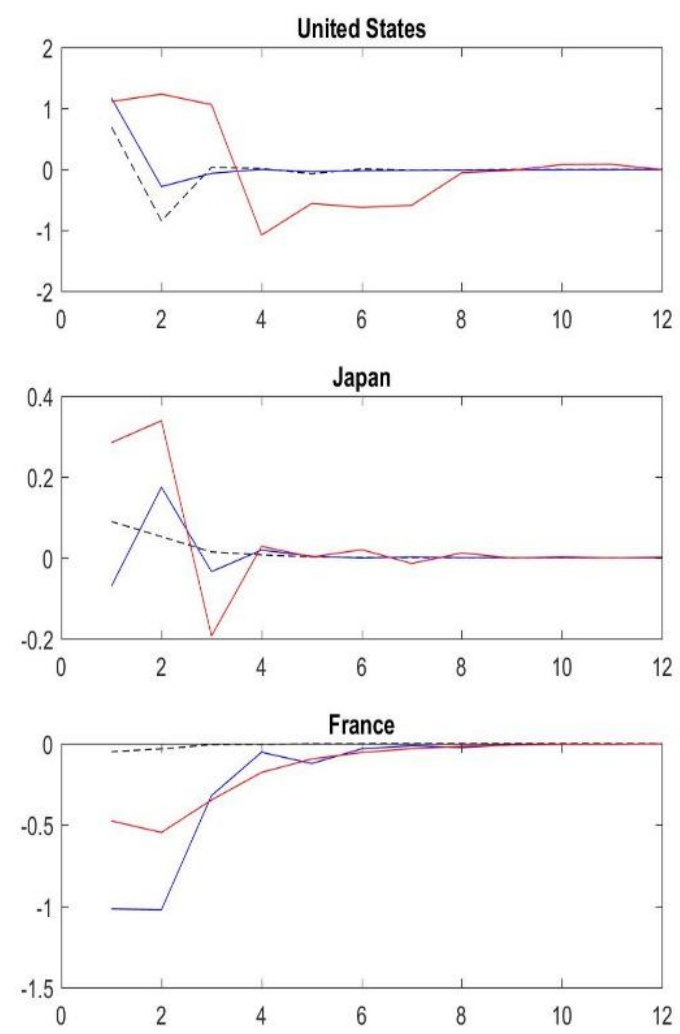

Oil exporting countries
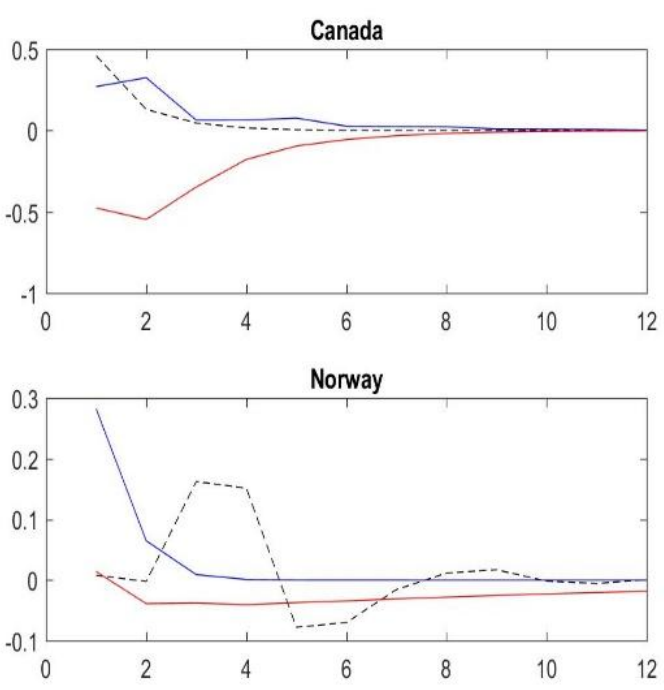

United Kingdom

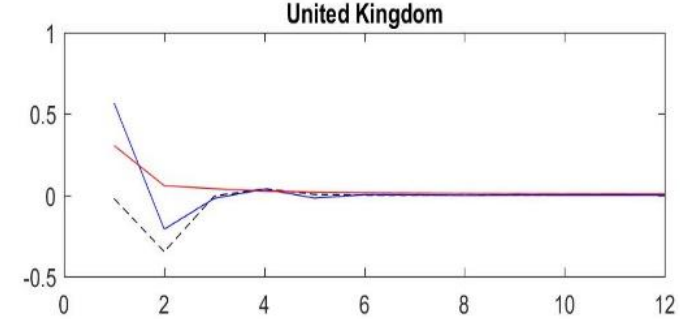

Note: The dashed black lines are impulse responses generated by the SVAR model with oil price uncertainty, blue lines are generated by the SFVAR model with oil price uncertainty, and the red lines are generated by the SFVAR model with both oil price and real uncertainties. The response in output growth is with respect to a $1 \%$ increase in oil price. 


\section{Figure 4: Factor estimates and smoothed factor estimates of the six countries}
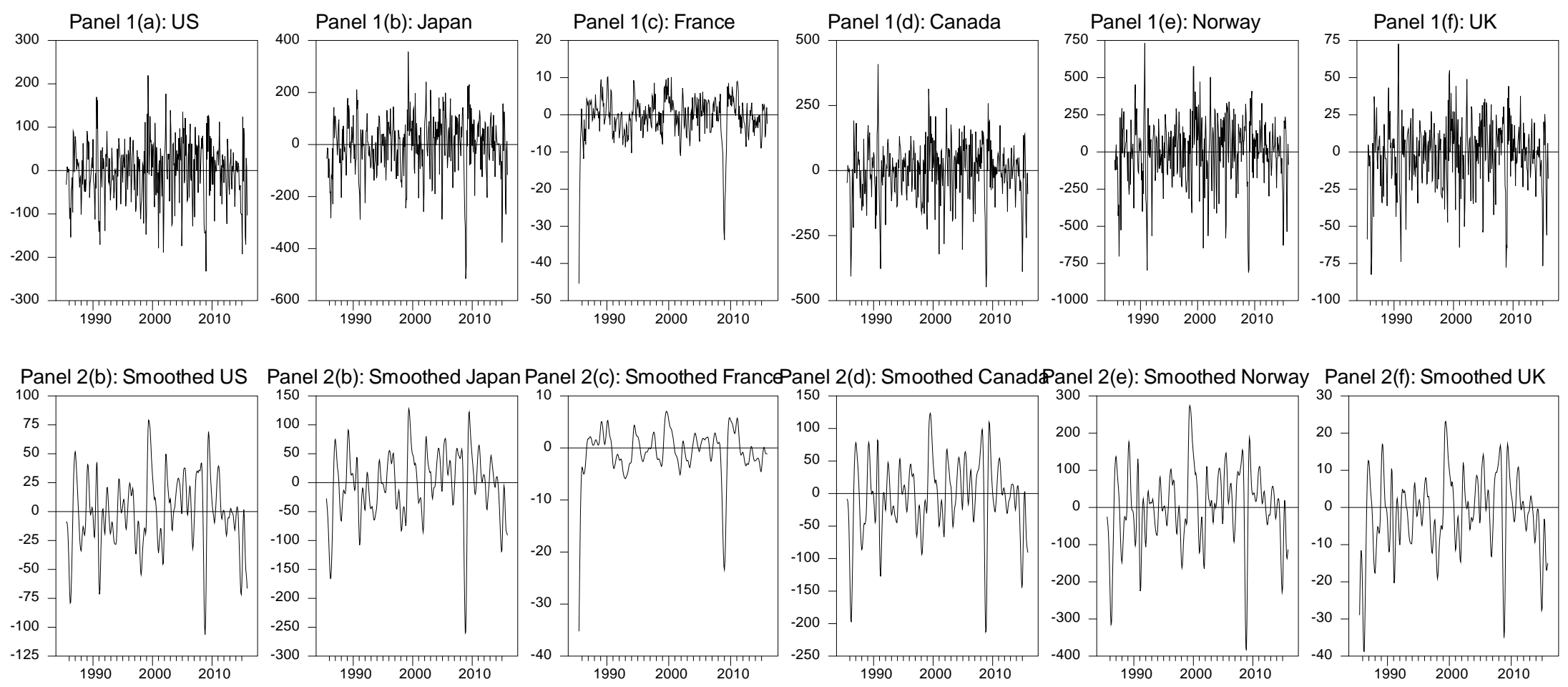

Note: The smoothed factor series are obtained using the Hodrick-Prescott band-pass filter. 


\section{Appendix}

Bry and Boschan (1971) provide a nonparametric, intuitive and easily implementable algorithm to determine peaks and troughs in individual time series, based on Burns-Mitchell rules for identifying specific cycles, expressing in terms of duration and amplitude. Although the method is quite commonly used in the literature, we briefly sketch its main sequential steps here. ${ }^{21}$ First, on the basis of some well-specified criterion, extreme observations are identified and replaced by corrected values. Second, troughs (peaks) are determined for a 12month moving average of the original series as observations whose values are lower (higher) than those of the five preceding and the five following months. In case two or more consecutive troughs (peaks) are found, only the lowest (highest) is retained. Third, after computing some weighted moving average, the highest and lowest points on this curve in the \pm 5 monthsneighborhood of the previously determined peaks and troughs are selected. If they verify some phase length criteria and the alternation of peaks and troughs, these are chosen as the intermediate turning points. Fourth, the same procedure is repeated using an unweighted short-term moving average of the original series. Finally, in the neighborhood of these intermediate turning points, troughs and peaks are determined in the unsmoothed time series. If these pass a set of duration and amplitude restrictions, they are selected as the final turning points. The adherent analytical steps and set of decision rules for selecting turning points are summarized in the table below.

${ }^{21}$ For a detailed description, the reader is referred to Bry and Boschan (1971). 
Table A1: Bry-Boschan procedure for determining turning points.

\begin{tabular}{|c|c|}
\hline Step & Procedure \\
\hline 1 & Determination of extremes and substitution of values \\
\hline 2 & $\begin{array}{l}\text { Determination of cycles in } 12 \text { month moving average (extremes replaced) } \\
\text { (A) Identification of higher (or lower) than } 5 \text { months on either side } \\
\text { (B) Enforcement of alternation of turns by selecting highest of multiple peaks } \\
\text { (or lowest of multiple troughs) }\end{array}$ \\
\hline 3 & $\begin{array}{l}\text { Determination of corresponding turns in Spencer curve (extremes replaced) } \\
\text { (A) Identification of highest (or lowest) value within } \pm 5 \text { months of selected } \\
\text { turn in } 12 \text { month moving average } \\
\text { (B) Enforcement of minimum cycle duration of } 15 \text { months by eliminating } \\
\text { lower peaks and higher troughs of shorter cycles }\end{array}$ \\
\hline 4 & $\begin{array}{l}\text { Determination of corresponding turns in short-term moving average of three } \\
\text { to } 6 \text { months, depending on months of cyclical dominance (MCD) } \\
\text { (A) Identification of highest (or lowest) value within } \pm 5 \text { months of selected } \\
\text { turn in Spencer curve }\end{array}$ \\
\hline 5 & $\begin{array}{l}\text { Determination of turning points in unsmoothed series } \\
\text { (A) Identification of highest (or lowest) value within } \pm 4 \text { months, or } \\
\text { MCD term, whichever is larger, of selected turn in short term } \\
\text { moving average } \\
\text { (B) Elimination of turns within } 6 \text { months of beginning and end of series } \\
\text { (C) Elimination of peaks (or troughs) at both ends of series which are } \\
\text { (D) Elimination of cycles whose duration is less than } 15 \text { months } \\
\text { (E) Elimination of phases whose duration is less than } 5 \text { months }\end{array}$ \\
\hline 6 & Statement of final turning points \\
\hline
\end{tabular}

Source: Bry and Boschan (1971, p. 21). 